\title{
Age-related changes in Tau and Autophagy in human brain in the absence of neurodegeneration
}

\author{
Shreyasi Chatterjee ${ }^{1 \dagger}$, Megan Sealey ${ }^{1 \dagger}$, Eva Ruiz ${ }^{1}$, Chrysia M. Pegasiou ${ }^{1,4}$, Sam \\ Green $^{1}$, Anna Crisford ${ }^{1}$, Michael Duque Vasquez ${ }^{1}$, Emma Luckett ${ }^{1}, 5$, Rebecca \\ Robertson1, Philippa Richardson ${ }^{1}$, Girish Vajramani², Paul Grundy², Diederik \\ Bulters $^{2,3}$, Christopher Proud ${ }^{1,6}$ Mariana Vargas-Caballero ${ }^{1 *}$ and Amritpal Mudher ${ }^{1 *}$
}

\section{Affiliations}

${ }^{1}$ School of Biological Sciences, University of Southampton, Southampton, SO17 1BJ, UK, ${ }^{2}$ Department of Neurosurgery, Wessex Neurological Centre, University Hospital Southampton, Southampton, SO16 6YD, UK, ${ }^{3}$ Clinical Neurosciences, Clinical and Experimental Sciences, Faculty of Medicine, University of Southampton, Southampton, SO16 6YD, UK, ${ }^{4}$ School of Life Sciences, University of Sussex, Brighton, BN1 9QG, ${ }^{5}$ Department of Neuroscience, KU Leuven, Leuven, Belgium. ${ }^{6}$ Lifelong Health. South Australian Health and Medical Research Institute; SAHMRI, and School of Biological Sciences, University of Adelaide, Adelaide, Australia.

\section{$\underline{\text { Key words }}$}

Tau, Autophagy, Human brain, Drosophila

${ }^{*}$ To whom correspondence should be addressed

Professor. Amritpal Mudher

E-mail: A.Mudher@soton.ac.uk

Dr. Mariana Vargas-Caballero

E-mail: M.Vargas-Caballero@soton.ac.uk

Present address: ${ }^{1}$ School of Biological Sciences, University of Southampton, Southampton, SO17 1BJ, UK

$\uparrow$ These authors contributed equally to this work 


\section{Abstract}

Tau becomes abnormally hyper-phosphorylated and aggregated in tauopathies like Alzheimers disease (AD). As age is the greatest risk factor for developing $A D$, it is important to understand how tau protein itself, and the pathways implicated in its turnover, change during aging. We investigated age-related changes in total and phosphorylated tau in brain samples from two cohorts of cognitively normal individuals spanning 19-74 years, without overt neurodegeneration. One cohort utilised resected tissue and the other used post-mortem tissue. Total soluble tau levels declined with age in both cohorts. Phosphorylated tau was undetectable in the post-mortem tissue but was clearly evident in the resected tissue and did not undergo significant agerelated change. To ascertain if the decline in soluble tau was correlated with agerelated changes in autophagy, three markers of autophagy were tested but only two appeared to increase with age and the third was unchanged. This implies that in individuals who do not develop neurodegeneration, there is an age-related reduction in soluble tau which could potentially be due to age-related changes in autophagy. Thus, to explore how an age-related increase in autophagy might influence taumediated dysfunctions in vivo, autophagy was enhanced in a Drosophila model and all age-related tau phenotypes were significantly ameliorated. These data shed light on age-related physiological changes in proteins implicated in AD and highlights the need to study pathways that may be responsible for these changes. It also demonstrates the therapeutic potential of interventions that upregulate turnover of aggregate-prone proteins during aging. 


\section{INTRODUCTION}

Alzheimer's disease (AD) is the most common cause of dementia in the elderly, and with a growing population of older people, it is becoming increasingly more prevalent. Age is one of the greatest risk factors for developing $A D$, with incidence increasing from 1 in 14 above that age of 65 to 1 in 6 at age $>80$ (Alzheimer's Association report 2019). This clearly demonstrates that age is a significant risk factor for developing this condition.

Since many of the neuropathological hallmarks of $A D$ and the clinical features that characterise it, such as declining working memory, short-term recall and processing speed, are also observed in normal aging $(1,2,3)$, it has been proposed that these agerelated changes are a continuum of $A D$ (4). However, the relationship between aging and $A D$ is complex and interwoven, and though there are many areas of overlap (5), it is clear that AD is not an inevitable part of the physiological CNS aging process (6). It therefore becomes imperative to understand what about the aging brain makes it vulnerable to $A D$ compared to the younger brain; to understand the physiological changes that occur in aging brains and the possible mechanisms by which deviation from the normal aging process occurs and leads to pathology and neurodegenerative disease. This topic has been the subject of numerous reviews, each discussing the many theories that have been proposed to explain how aging confers risk of $A D$ and other age-related proteinopathies $(5,7)$. One area of interest in this regard is the role of proteostatic pathways such as autophagy. Both macro-autophagy and chaperonemediated autophagy are implicated in the turnover of tau, the microtubule associated protein that constitutes the neurofibrillary tangles, one of the two defining pathological hallmarks of $\operatorname{AD}(50,59,65,80,81,82)$. The consensus view is that there is a functional decline in autophagic clearance capabilities in the brains of individuals who are affected by neurodegenerative proteinopathies, and this manifests in the accumulation of misfolded protein aggregates $(8,9)$. Many mechanisms have been proposed to account for this functional decline. A leading view, supported by a large body of evidence, is that autophagy is activated as a reactive response to misfolded protein formation at early stages of disease, but that the pathogenic proteins have a toxic effect on autophagy, compromising it such that it eventually becomes overwhelmed in 
proteinopathies (10). Another view is that with increasing age, there is reduced autophagy and this is conducive to promoting aggregation and accumulation of misfolded proteins in the aged brain (11). While many studies have demonstrated impaired autophagy in the brains of neurodegenerative disease patients, there are relatively few studies investigating normal physiological changes in basal autophagy with increasing age in the absence of neurodegeneration (11).

In a similar vein, very few studies have shown how proteins like tau, which accumulate and misfold in Tauopathies and are believed to be substrates for autophagy, actually change physiologically in the human brain during healthy aging without the confounding influences of underlying neurodegeneration. The only study that assessed this in human brain was published over 20 years ago and reported a decrease in total soluble tau levels (1). Though a mechanism was not demonstrated, that study nonetheless showed that the decrease in soluble tau was not due to a reciprocal age-related increase in insoluble tau.

The current study addresses these questions by investigating physiological agerelated changes in both tau and autophagy in human brain samples taken from young and old subjects who did not have any neurodegenerative disease. In agreement with the study by Mukaetova-Ladinska et al (36), our findings also suggest that with increasing age, total soluble tau levels decline. Strengthening that previous finding, we demonstrate that this reduction in tau is seen in resected human brain tissue as well as post-mortem brain, confirming that it is not due to a post-mortem artefact. We then go on to investigate if this change in total soluble tau could be explained by an age-related change in autophagy; though we do demonstrate an increase in expression of some markers of autophagy in older brains, others are unchanged. This data implied that an age-related increase in autophagy could influence total soluble tau levels and protect against tau-mediated neurodegeneration. To test this, a Drosophila model was employed in which co-expression of a pro-autophagic gene was found to significantly improve age-related tau phenotypes. 


\section{MATERIALS AND METHODS}

\section{Human Tissue Samples}

Samples of frozen cortical sections from post-mortem human brains (six 20-33 year old brains and seven 70-74 year old brains) were obtained from Sudden Death Brain Bank (Edinburgh, United Kingdom, cortical area: superior temporal gyrus, case numbers included: SD023/08, SD041/05, SD027/06, SD034/08, SD030/09, SD001/11, SD008/12, SD020/06, SD053/14, SD025/17, SD024/17, SD012/17, SD008/17). No pathological diagnosis of Alzheimer's Disease or any other pathology was reported in these tissues.

Resected human Brain tissue was obtained during neurosurgical procedures at the Wessex Neurological Centre at University Hospital Southampton and the samples were processed according to the Human Tissue Act 2004 with approval from the Faculty of Medicine Ethics Committee and the Southampton Research Biorepository following written informed consent (Study reference number SRB002/14). The patients were being treated for medial temporal epilepsy, cavernous or arteriovenous malformations or glioma (Table 1). Any surplus tissue that was removed for access to these lesions that would otherwise be discarded was retained and subsequently processed as described by Pegasiou et al. (12). Following resection cortical tissue was immediately put into artificial cerebrospinal fluid (ACSF) $(110 \mathrm{mM}$ choline chloride, $26 \mathrm{mM} \mathrm{NaHCO} 3,10 \mathrm{mM}$ D-glucose, $116 \mathrm{mM} \mathrm{C}_{6} \mathrm{H}_{7} \mathrm{NaO}_{6}, 7 \mathrm{mM} \mathrm{MgCl}$, 3.1 $\mathrm{mM} \mathrm{C}_{3} \mathrm{H}_{3} \mathrm{NaO}_{3}, 2.5 \mathrm{mM} \mathrm{KCl}, 1.25 \mathrm{mM} \mathrm{NaH}_{2} \mathrm{PO}_{4}$ and $0.5 \mathrm{mM} \mathrm{CaCl}_{2}$.) The tissues were collected from patients in the age group 19 to 70 years and age-matched with the postmortem brain samples. Thirteen samples were used for our experiments. These tissues were snap frozen on dry ice within 10 min of removal from the patient.

Both post-mortem and resected tissue samples were then lysed in homogenization buffer (10 mM Tris Base, $150 \mathrm{mM} \mathrm{NaCl}, 0.05 \%$ Tween-20, 1mM Na orthovanadate, $10 \mathrm{mM} \mathrm{NaF}, 10 \mu \mathrm{M}$ Staurosporine, 1X Protease Inhibitor cocktail and $1 \mathrm{mM}$ Tyrophostin) on ice. The samples were spun briefly at $8000 \times g$ for $5 \mathrm{~min}$ and the pellets were discarded. A protein assay was conducted by the Bradford method to 
normalize the protein concentration. The samples were then boiled for in 2x SDS sample buffer at $95^{\circ} \mathrm{C}$ for 5 min for subsequent Western Blotting analysis.

\section{Electrophysiology}

Following previously published methods (79), slices were transferred to a submergedstyle recording chamber and superfused with recording ACSF at a rate of $\sim 1.5$ $\mathrm{mL} / \mathrm{min}$. Whole-cell voltage clamp recordings were performed using glass pipettes ( $\sim 5$ $\mathrm{M} \Omega$ ) pulled from borosilicate glass, yielding a series resistance of $\sim 15 \mathrm{M} \Omega$. Recordings were made at room temperature $\left(21-25^{\circ} \mathrm{C}\right)$ using K-gluconate-based intracellular solution, containing (in mM): 120 Potassium gluconate; $10 \mathrm{KCl}$; 10 Hepes; $0.3 \mathrm{GTP} ; 4$ Mg-ATP; and $\mathrm{pH}$ was titrated to 7.25 with $\mathrm{KOH}$. The final osmolarity was 285 $\mathrm{mOsmol}^{-1}$. Neuronal excitability was tested by delivering square pulses of current in increments of $50 \mathrm{pA}$.

\section{Electron Microscopy}

Sections of freshly resected cortex were placed into a fixative solution consisting of 3 $\%$ glutaraldehyde and $4 \%$ formaldehyde in $0.1 \mathrm{M} \mathrm{PIPES}$ and stored at $4^{\circ} \mathrm{C}$ for a minimum of $1 \mathrm{~h}$. Brain samples, approx. $1 \mathrm{~mm}$ by $1 \mathrm{~mm}$ in size, were washed with 0.1 M PIPES and then incubated in $1 \%$ osmium tetroxide for $1 \mathrm{~h}$. After further washes in 0.1 M PIPES, samples were incubated in $2 \%$ uranyl acetate for 20 min. Dehydration followed using increasing concentrations of ethanol. After a final incubation in acetonitrile for $10 \mathrm{~min}$, samples were incubated overnight in 50:50 acetonitrile:TAAB resin. Samples were then incubated for $6 \mathrm{~h}$ in TAAB resin and were then left to polymerise for $24 \mathrm{~h}$ at $60^{\circ} \mathrm{C} .90-100 \mathrm{~nm}$ sections were produced from the samples using the Reichert OM-U3 ultra-microtome and placed onto copper palladium grids. Samples were then placed onto droplets of lead citrate for 3 - 5 min for further contrast before being imaged at $\times 87,000$ magnification using an FEI Tecnai T12 transmission electron microscope.

\section{Western Blotting}

Human brain samples: 20 to $30 \mu \mathrm{g}$ of the homogenates were separated on $10 \%$ SDSPAGE gels and transferred to nitrocellulose membranes/PVDF membranes. After 
blocking the membranes in 5\% BSA in 1 X TBS, these were incubated overnight at $4^{\circ} \mathrm{C}$ with the following antibodies. Anti-human tau (Dako, 1:10,000), the phosphorylation specific anti-tau antibody Ser396/Ser404 (PHF1, 1:500) (a gift from Dr. Peter Davies, USA), Acetylated $\alpha$-tubulin (Sigma Aldrich, 1:1000), Tyrosinated $\alpha$-tubulin (Sigma Aldrich, 1:2000), Total $\alpha$-tubulin (Sigma Aldrich, 1:1000), p62 (Millipore, 1:1000) and LC3 (Abcam, 1:500), GAPDH (Abcam, 1:2500), Beclin1 (Abcam, 1:500) Rabbit $\beta$-actin (Abcam, 1:3000) and Mouse $\beta$-actin (Abcam, 1:1000) were used as loading controls. Membranes were then incubated with secondary antibodies (Alexa Fluor 680 goat anti-mouse or Alexa Fluor 800 goat anti-rabbit) at 1:20,000 for one hour at room temperature. Antigens were visualised using an Odyssey scanner (Li-Cor Biosciences).

Fly brain samples: Adult flies were snap frozen in liquid nitrogen and fly heads were dissected. Ten fly heads were then homogenized in homogenization buffer in a ratio of 1 head: $10 \mu$ buffer $(150 \mathrm{mM} \mathrm{NaCl}, 50 \mathrm{mM}$ MES, 1\% Triton-X, protease inhibitor cocktail, 30 mM NaF, 40 mM 2-glycerophosphate, 20 mM Na-pyrophosphate, $3.5 \mathrm{mM}$ $\mathrm{Na}$ orthovanadate, $1 \%$ SDS, $10 \mu \mathrm{M}$ Staurosporine). Samples were centrifuged at 3000 $x g$ and pellets were discarded. 2x SDS sample buffer was added to each tube and boiled at $95^{\circ} \mathrm{C}$ for $5 \mathrm{~min}$. Western Blotting was then done as described above.

\section{Fly Stocks}

Elav-GeneSwitch, UAS-hTau ${ }^{0 N 3 R}$, UAS-Atg1 were obtained from Bloomington Drosophila Stock Center, Indiana, US. Bigenic flies (UAS-hTau ${ }^{0 N 3 R / U A S-A t g 1) ~ w e r e ~}$ created using standard genetic recombination methods. The flies were raised and maintained at $25^{\circ} \mathrm{C}$ on SYA diet using standard protocols.

\section{$\underline{\mathrm{RU} 486 \text { treatment }}$}

A 100 mM stock solution of RU486 was prepared in 100\% ethanol. Post eclosion, 0-3 day-old flies were moved to either food containing $200 \mu \mathrm{M}$ RU486 or to control diet for biochemistry and behavioural studies; this was to ensure gene expression was switched on only in adult flies. Only male flies were used for our studies to remove confounding impact of egg laying in the climbing assay that was done in these animals. 


\section{Climbing Assay}

The climbing assay was performed according to standard procedures developed in our laboratory (13). Briefly, five cohorts of 50 flies were transferred to $50 \mathrm{ml}$ measuring cylinders without anasthetisation and the distance climbed was recorded at 10 seconds after tapping down. The assays was repeated three times with 1 min rest between each trial and the mean was calculated.

\section{Statistics}

GraphPad Prism 5.0 software was used for statistical analysis. Two-tailed t tests were used to analyse the difference between two groups. For multiple comparisons oneway or two-way ANOVA with Bonferroni's post-hoc correction for pairwise comparisons was used. Error bars depict standard error of the mean (SEM) as indicated in the figure legend. Statistical significance is depicted by the following n.s = not significant $(p>0.05),{ }^{*} p<0.05,{ }^{* *} p<0.01,{ }^{* * *} p<0.001,{ }^{* * * *} p<0.0001$

\section{RESULTS}

\section{Resected human brain tissue is physiologically normal}

To study impact of aging on tau in the absence of neurodegeneration in human brain, total and phosphorylated levels were assessed in non-pathological cortical human brain tissues taken from young and old individuals assessed by routine neuropathological analysis and by the lack of inflammatory markers (12). Importantly, as previous studies $(14,15,16)$, including ones from our own lab (17), have demonstrated that the post-mortem (PM) interval influences the phosphorylation state of tau, our initial studies were conducted both in resected human tissue following collection in the operating theatre and rapid processing (no PM interval) as well as in human tissue from national brain banks (standard PM interval). Resected tissue was collected at the neurosurgery unit of University Hospital Southampton from a spectrum of surgical cases ranging from 19 to 70 years of age. Tissue was either quickly frozen and kept at $-80^{\circ} \mathrm{C}$ or processed for electrophysiology or electron microscopy (see methods). As described recently (12), the tissue utilised for these studies was physiologically and morphologically normal unless otherwise indicated. The rapid collection permits the preservation of function and ultrastructure. We are confident that 
the resected tissue that we have utilised in this study represents normal physiological tissue without confounding disease. This is illustrated in supplementary Fig. 1 where an electrophysiological recording taken from one such case (Suppl. Fig. 1A) showing robust action potential firing as a response to depolarising current injection, together with an ultra-structural image showing pre and postsynaptic structures (Suppl. Fig. 1B). Further electrophysiological recordings on these resected human tissue are shown in Pegasiou et al 2020, Table 1. Since resected tissue is a precious and scarce resource, only the analyses of total and phosphorylated tau, which we know from previous findings are sensitive to PM delay (86), were conducted using this tissue.

\section{Age dependent decrease in total tau in non AD brain}

Post-mortem cortical human brain tissues from individuals without $A D$ or other neurodegenerative disorders were obtained from the Sudden Death Brain Bank (Centre for Clinical Brain Sciences, Edinburgh, UK). These tissues were divided into young (aged 20 to 33 years) and elderly cohorts (aged 70 to 74 years) and age-related alterations in the levels of total and phospho-tau were assessed by western blotting. The post mortem intervals in the young and old cohorts were not significantly different $(p=0.48)$. Similarly, age-matched cortical resected tissues were freshly collected from individuals ranging in age from 19 to 70 years who were undergoing surgery (Wessex Neurological Centre, University Hospital Southampton) but did not have neurodegenerative disease. As with the post-mortem tissue, the resected tissues were divided into young (aged 19 to 42 years) and old cohorts (aged older brains 50-70 years). Due to limited availability, the resected human tissue could not be segregated into very young and very old, in contrast to the PM tissue, where samples of desired ages could be requested from brain banks. Nonetheless, the segregation of the resected tissue into young and old brain groups was performed based on previous findings that cognitive decline begins from 45 years onwards (98).

A significant decrease $(p<0.0001)$ in the levels of total tau was observed in the postmortem brain samples from the older cohorts compared to the younger cohorts (Fig. $1 \mathrm{~A} \mathrm{i}$ and $\mathrm{iii}$. This significant reduction in total soluble tau levels with increasing age was also observed in age-matched resected tissues $(\mathrm{p}<0.05)$ (Fig. 1B i and ii). Interestingly, a robust phospho-tau signal (immunoreactive to the PHF1 antibody) was 
evident in resected tissues (Fig. 1B i), but no such signal was detected in the postmortem tissues (Fig. 1A i) possibly due to the post-mortem delay. We did not observe a significant age-dependent increase of PHF-tau signal in the resected tissues (Fig. 1B iii). The observation of robust PHF-1 positive tau in non-AD brain is unusual as tau is not believed to be significantly phosphorylated in normal adult brain (i.e., in the absence of neurodegeneration). This demonstrates the advantage of comparing signals in resected and PM tissues alongside each other to identify changes that may otherwise of be lost due to tissue processing and PM delay.

In order to confirm that the decrease in total tau levels in the older cohorts is not due to an age-related loss of neurons, the level of the neuronal marker NeuN was assessed by western blotting. No significant difference in NeuN levels was observed between the younger and older cohorts (Fig. 1A ii and iii). Thus, we can conclude that the age-dependent decrease in the total soluble tau levels is not due to neuronal loss.

We next wanted to test whether the change in tau is correlated with an age-related alteration in tau-mediated function.

\section{Post-Mortem Brain Tissue Case Data}

\begin{tabular}{|l|l|l|l|l|l|}
\hline $\begin{array}{l}\text { Case } \\
\text { Number }\end{array}$ & Sex & Age & Diagnosis & $\begin{array}{l}\text { Other } \\
\text { Medical } \\
\text { History }\end{array}$ & Brainarea \\
\hline SD023/08 & F & 24 & $\begin{array}{l}\text { Small vessel } \\
\text { disease }\end{array}$ & Not known & Temporal lobe \\
\hline SD041/05 & M & 24 & $\begin{array}{l}\text { No significant } \\
\text { abnormality }\end{array}$ & Not known & Temporal lobe \\
\hline SD027/06 & M & 25 & $\begin{array}{l}\text { Cerebral } \\
\text { oedema. Recent } \\
\text { hypoxia. History } \\
\text { of butane gas } \\
\text { inhalation. }\end{array}$ & Not known & Temporal lobe \\
\hline SD034/08 & M & 70 & $\begin{array}{l}\text { No significant } \\
\text { abnormality }\end{array}$ & Not known & Temporal lobe \\
\hline SD030/09 & $\mathrm{F}$ & 71 & $\begin{array}{l}\text { No significant } \\
\text { abnormality }\end{array}$ & Not known & Temporal lobe \\
\hline SD001/11 & M & 74 & $\begin{array}{l}\text { No significant } \\
\text { abnormality }\end{array}$ & Not known & Temporal lobe \\
\hline SD008/12 & M & 25 & $\begin{array}{l}\text { No } \\
\text { neuropathological } \\
\text { findings }\end{array}$ & Not known & Temporal \\
\hline
\end{tabular}




\begin{tabular}{|l|l|l|l|l|l|}
\hline SD020/06 & F & 20 & $\begin{array}{l}\text { No significant } \\
\text { abnormality }\end{array}$ & Not known & $\begin{array}{l}\text { Temporal } \\
\text { Superior }\end{array}$ \\
\hline SD053/14 & M & 33 & $\begin{array}{l}\text { No significant } \\
\text { abnormalities }\end{array}$ & Not known & $\begin{array}{l}\text { Superior } \\
\text { temporal } \\
\text { gyrus BA41/42 }\end{array}$ \\
\hline SD025/17 & M & 73 & $\begin{array}{l}\text { No significant } \\
\text { abnormalities }\end{array}$ & Not known & $\begin{array}{l}\text { Superior } \\
\text { temporalgyrus } \\
\text { BA41/42 }\end{array}$ \\
\hline SD024/17 & M & 72 & $\begin{array}{l}\text { No significant } \\
\text { abnormalities }\end{array}$ & Not known & $\begin{array}{l}\text { Superior } \\
\text { temporalgyrus } \\
\text { BA41/42 }\end{array}$ \\
\hline SD012/17 & F & 71 & $\begin{array}{l}\text { No significant } \\
\text { abnormalities }\end{array}$ & Not known & $\begin{array}{l}\text { Superior } \\
\text { temporalgyrus } \\
\text { BA41/42 }\end{array}$ \\
\hline SD008/17 & F & 71 & $\begin{array}{l}\text { No significant } \\
\text { abnormalities }\end{array}$ & Not known & $\begin{array}{l}\text { Superior } \\
\text { temporalgyrus } \\
\text { BA41/42 }\end{array}$ \\
\hline
\end{tabular}

\section{Resected Tissue Case Data}

\begin{tabular}{|c|c|c|c|c|c|}
\hline $\begin{array}{l}\text { Case } \\
\text { Number }\end{array}$ & Sex & Age & Diagnosis & $\begin{array}{l}\text { Other Medical } \\
\text { History }\end{array}$ & Brain area \\
\hline 0019 & $M$ & 19 & $\begin{array}{l}\text { Arteriovenous } \\
\text { malformation }\end{array}$ & Not known & Left frontal lobe \\
\hline 0026 & $\mathrm{M}$ & 27 & $\begin{array}{l}\text { Mesial temporal } \\
\text { DNET with } \\
\text { signal changes } \\
\text { in the } \\
\text { hippocampus }\end{array}$ & Not known & $\begin{array}{l}\text { Right anterior } \\
\text { temporal lobe }\end{array}$ \\
\hline 0014 & $M$ & 32 & $\begin{array}{l}\text { Hippocampal } \\
\text { Sclerosis }\end{array}$ & Not known & $\begin{array}{l}\text { Left anterior } \\
\text { temporal lobe }\end{array}$ \\
\hline 0023 & $\mathrm{M}$ & 35 & Cavernoma & Not known & Left frontal lobe \\
\hline 0016 & $F$ & 36 & $\begin{array}{l}\text { Hippocampal } \\
\text { sclerosis }\end{array}$ & Not known & $\begin{array}{l}\text { Right anterior } \\
\text { temporal lobe }\end{array}$ \\
\hline 0028 & $F$ & 38 & Epilepsy & Asthma & $\begin{array}{l}\text { Right anterior } \\
\text { temporal lobe }\end{array}$ \\
\hline 0011 & $F$ & 42 & Glioma & Not known & $\begin{array}{l}\text { Left anterior } \\
\text { temporal lobe }\end{array}$ \\
\hline 0024 & $F$ & 50 & $\begin{array}{l}\text { Cavernous } \\
\text { malformation }\end{array}$ & Not known & $\begin{array}{l}\text { Right lateral } \\
\text { temporal lobe }\end{array}$ \\
\hline 0012 & $\mathrm{M}$ & 55 & Glioblastoma & Not known & Left parietal lobe \\
\hline 0017 & $\mathrm{~F}$ & 62 & $\begin{array}{l}\text { Hippocampal } \\
\text { Sclerosis }\end{array}$ & $\begin{array}{l}\text { Depression, } \\
\text { hypertension, } \\
\text { gastroreflux disease }\end{array}$ & $\begin{array}{l}\text { Right anterior } \\
\text { temporal lobe }\end{array}$ \\
\hline
\end{tabular}




\begin{tabular}{|l|l|l|l|l|l|}
\hline 0025 & F & 62 & $\begin{array}{l}\text { Metastasis - } \\
\text { Adenocarcinoma } \\
\text { of the lung }\end{array}$ & Not known & Right frontal lobe \\
\hline 0013 & F & 69 & $\begin{array}{l}\text { High Grade } \\
\text { Glioma }\end{array}$ & Not known & Right frontal lobe \\
\hline 0020 & F & 70 & $\begin{array}{l}\text { Arteriovenous } \\
\text { malformation }\end{array}$ & $\begin{array}{l}\text { Hysterectomy, } \\
\text { urostomy, acute } \\
\text { myocardial infarction, } \\
\text { hypertension, } \\
\text { polymyalgia } \\
\text { rheumatic, } \\
\text { hypercholesteromia, } \\
\text { recurrent urinary tract } \\
\text { infections }\end{array}$ & $\begin{array}{l}\text { Right lateral } \\
\text { temporal lobe } \\
\text { (superior temporal } \\
\text { gyrus) }\end{array}$ \\
\hline
\end{tabular}

\section{Microtubule stability measures are similar in young and old brains}

One of the primary functions of tau is the binding and polymerization of microtubules $(18,19)$. It has been shown that the hyperphosphorylated and PHF tau in AD brains can reduce the number and length of microtubules (20). Further, it has also been shown that microtubule-stabilizing drugs are able to reverse axonal defects in animal models of tauopathy suggesting a direct connection between pathological tau and microtubule dysfunction (21). In order to assess whether the loss of tau in the elderly cohorts compromises its function of polymerization and stabilization of neuronal microtubules, the levels of acetylated and tyrosinated alpha tubulin were assessed by western blotting. These post-translational modifications of tubulin are common indicators of microtubular integrity (22). While acetylation is a marker for the stability of microtubules, tyrosination of tubulin has been shown to influence neuronal organization $(22,23)$. No difference in the levels of acetylated tubulin (Fig. 2A i and ii) or tyrosinated tubulin (Fig. 2B i and ii) was detected between the younger and elderly cohorts in the post-mortem brain samples. This implies that despite the decrease in cortical tau levels in healthy elderly cohorts, the stability of the microtubules in the same brain region is not affected.

\section{Late autophagy markers are significantly increased in the post- mortem brains of the elderly cohorts compared to the younger cohorts}


To investigate the potential cause for the age-related decline in total tau levels, markers of autophagy were studied in the young and old post-mortem brain samples. p62 is a classical autophagy marker, its function being the ubiquitination of a host of cellular proteins that are then targeted for degradation (24). As it is destroyed during autophagy, accumulation of p62 implies an impairment of autophagy while a reduction of p62 is indicative of activated autophagic. A significant decrease of p62 $(p<0.05)$ was evident in the post-mortem brains of the older cohorts compared to the younger cohorts (Fig.3A i and ii). As there is no significant difference in the PM delay in these samples which may be influence this readout, these results potentially point to increased markers of autophagy in the brains of the elderly cohorts.

To investigate this further, additional markers of autophagy were investigated. In mammalian systems, another classical marker for late-stage autophagosome formation is the lysosomal marker LC3-II, and an increase in this signifies an enhancement of autophagy (25). In addition to decreased p62, a significant increase in the LC3-II/LC3-I ratio $(\mathrm{p}<0.05)$ as well as an increase in total LC3-II levels was evident in the older post-mortem brains compared to the younger brain tissues (Fig.3B i-iii).

Since both p62 and LC3II/I ratios are markers of late-stage autophagy, we next investigated whether early stage markers were also altered with age. For this we assessed levels of Beclin 1, a key autophagy protein known to be decreased in AD brains (26). Interestingly, we did not see a significant difference in the levels of this early autophagy marker - neither did this marker go up or down with age in our young and old non-AD cohorts (Fig. 4 i and ii).

Taken together our results indicate that expression of some late-stage autophagy markers is increased in the older compared to the younger cohorts. However as the one early stage marker we examined appeared unaltered, it is not clear how overall autophagy changes with age, in the absence of neurodegeneration. Nonetheless it is clear that there is no age-related decline in autophagy as has been the consensus view. 


\section{Age-related tau-induced behavioural changes are suppressed by activation of autophagy in a Drosophila model of Tauopathy}

The data presented thus far show that in non-AD brains, soluble tau levels are decreased with age, whilst expression of some specific markers of autophagy is increased. One interpretation of this is that an age-related increase in autophagy is a normal physiological response to aging which likely prevents the accumulation of total tau and protects against formation of tau aggregates in non-demented elderly subjects. To test this hypothesis, we assessed the impact of inducing autophagy on some age-related tau phenotypes in a Drosophila model of Tauopathy in which $\mathrm{hTau}{ }^{\mathrm{N} 3 \mathrm{R}}$ is expressed. In this model, autophagy was induced by upregulation of the autophagy-specific kinase gene Atg1 (27). To avoid developmental impact of inducing autophagy, pan-neuronal expression of both $\mathrm{hTau}^{\mathrm{N} 3 \mathrm{R}}$ and the autophagy gene manipulation was initiated in adults using the inducible GeneSwitch system in which the drug RU486 was fed to newly eclosed adults to induce expression in adult flies which were then aged for a 4 week period. In parallel, the tau/Atg1 bigenics were similarly fed RU486 upon ecclosion and aged for the same period of time. This treatment led to induction of expression of both $\mathrm{hTau}^{\mathrm{ON} 3 \mathrm{R}}$ and autophagy (Suppl. Fig. 2). With this mode of adult-onset $\mathrm{hTau}^{\mathrm{ON} 3 \mathrm{R}}$ expression, a significant age-related increase $(p<0.01)$ in phosphorylated tau was evident which was abrogated by coexpression of Atg1 (Fig. 5A i/ii).

We have previously demonstrated that overexpression of hTau ${ }^{0 N 3 R}$ using the nontemporally sensitive Elav-GAL4 pan-neural driver causes an age-dependent defect in the climbing ability of the flies (13). Such a reduction in climbing ability was beginning to emerge in the flies expressing $\mathrm{hTau}^{\mathrm{ON} 3 \mathrm{R}}$ following RU486 consumption, though it was less pronounced over the 4-week period tested, possibly because, with the GeneSwitch method employed here, tau expression only begins upon eclosion, but is likely to begin several days before eclosion with the Elav-Gal4 expression system previously used (Fig. 5B). Induction of autophagy by co-expression of Atg1 significantly $(p<0.0001)$ improved the climbing behaviour of the $h T a u^{0 N 3 R}$ flies. In young flies (up to $1 \mathrm{wk}$ old) there was no difference in the climbing ability of flies expressing $\mathrm{hTau}^{\mathrm{ON} 3 \mathrm{R}}$ alone when compared to $\mathrm{hTau}{ }^{\mathrm{ON} 3 \mathrm{R}}$ flies that co-expressed Atg1. However, as the $\mathrm{hTau}{ }^{\mathrm{N} 3 \mathrm{R}} / \mathrm{Atg} 1$ bigenics started aging, their climbing ability was 
significantly rescued by coexpression of Atg1 compared to the age-matched hTau ${ }^{0 N 3 R}$ flies alone. After 2 weeks, the climbing ability of the hTau ${ }^{0 N 3 R} / A t g 1$ bigenic animals became significantly better $(p<0.001)$ than that of $h T a u^{0 N 3 R}$ flies so that by 4 weeks their climbing was nearly $100 \%$ better $(p<0.0001)$. This effect was tau-specific and not a non-specific effect of over-expressing Atg1 since there was no similar agedependent improvement in the climbing ability of flies expressing Atg1 alone. These results show that induction of autophagy prevents the age-related accumulation of hyperphosphorylated tau and improves the climbing behaviour of tau-expressing flies in an age-related manner.

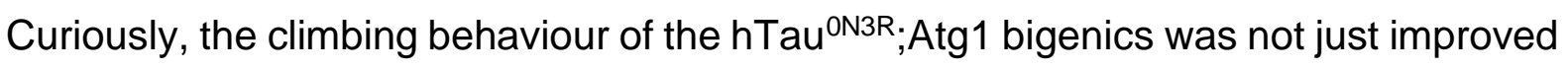
compared to those of either $\mathrm{hTau}{ }^{0 \mathrm{~N} 3 \mathrm{R}}$ or Atg1 alone flies, it was also better than the unexpressed bigenic controls. One potential explanation for this is that, as well as mediating a toxic effect, expression of hTau may have some other beneficial effect not evident in the unexpressed controls. One such effect may relate to endogenous Drosophila (dTau) as we have previously demonstrated that the two interact (87). To explore this, the impact of $\mathrm{hTau}{ }^{\mathrm{ON} 3 \mathrm{R}}$ expression on dTau was examined. dTau levels were found to accumulate with age in wild-type flies but not in flies expressing hTau ${ }^{0 N 3 R}$ (Suppl. Fig. 3). It is likely that, in the presence of hTau, endogenous dTau expression is reduced as a compensatory measure. Consequently any detrimental effects caused by dTau accumulation would not be evident in hTau expressing flies but would still be present in unexpressed controls (88).

\section{DISCUSSION}

Age is the biggest risk factor for Alzheimer's disease $(29,30)$ and yet the mechanism(s) by which increasing age confers risk of disease are not well understood. In this study the impact of age on total and phosphorylated tau levels was studied in human brain tissue taken from young and old subjects, together with an analysis of age-related changes in autophagy, a pathway implicated in tau clearance (31). With increasing age, a decrease in total tau levels and an increase in expression of two markers of autophagy were evident in the absence of overt neurodegeneration. In order to test the impact of increased autophagy on human tau during aging, autophagy was 
genetically upregulated and tau-related behavioral changes were studied in young and old transgenic Drosophila. Co-expression of an autophagy gene, Atg1, with human tau ameliorated the accumulation of phosphorylated tau and significantly improved their climbing behaviour in an age-related manner in this model. Collectively these data suggest that age-related increases in autophagy may prevent the accumulation of tau and thus protect against tau-mediated pathogenic changes in vivo. It remains to be seen whether this is the mechanism by which elderly individuals who do not develop AD are protected and is worthy of further investigation. Similarly, whether it is a deviation from this trait that leads to compromised autophagy in some individuals as they age which then causes tau accumulation and downstream degeneration also needs further exploration (Suppl. Fig. 4).

\section{Age-related changes in tau in non-AD brain}

Aging is defined as a time-dependent deterioration of the physiological functions of our body. Whilst the biological process of aging is complex and not well defined, it has been established that age is the primary risk factor for Alzheimer's Disease (AD) with $90 \%$ of the AD cases occurring when the patients are 65 years or older (Alzheimer's Association 2019). There are many theories to explain how aging confers risk of developing Alzheimer's disease $(5,6)$. One view is that the formation of neuritic plaques and neurofibrillary tangles with increasing age (32) is a continuum of $A D$ and that individuals with intermediate levels of these pathologies display mild cognitive symptoms whilst those with higher levels of pathology display full blown dementia (4). Though attractive, this view is challenged by the finding that a significant number of individuals with neuritic plaque and tangle pathology are not cognitively impaired $(33,34)$. This indicates that increased formation of such pathologies with increasing age cannot entirely explain how aging increases risk of developing dementia, and that other factors may also play a role (34).

Nonetheless, since there is a tight correlation between formation of neurofibrillary pathology and cognitive decline, it is worth investigating how tau proteins change in normal, non-demented individuals with increasing age. Whilst many studies have studied tau protein in brain and CSF from Alzheimer patients, and by default in most of these studies an analysis of age-matched controls is included, relatively few studies 
have assessed how tau protein itself changes with aging by directly comparing it in CNS tissues from young and old non-demented individuals. The data presented here demonstrates that total tau levels in cortical samples from older individuals are significantly reduced when compared to those found in younger individuals. This is likely to reflect an age-related decline in total soluble tau rather than a non-specific consequence of neuronal death during aging since the neuronal marker NeuN (35) does not change, indicating that there is no significant age-related neuronal loss in these cohorts, a phenomenon reported by others as well (5).

Our data cannot be attributed to brain-bank specific peculiarities in processing of tissues, as our samples were obtained from two distinct brain banks. Additionally our data is in agreement with one other study that has similarly compared tau levels in young and old non-cognitively impaired human brain samples. They also showed that soluble total tau levels decreased with age in individuals ranging from 19-88 years, but were not able to identify a potential mechanism, beyond demonstrating that there was no correlative increase in insoluble tau which might explain the reduction in soluble tau (36). As well as this, one more recent observation that also supports this result showed immunohistochemical decreases in tau in retinal biopsies taken from older subjects compared to those from younger subjects (89). Building on these findings, we show here that in the brain samples where soluble tau is decreased, there is also an age-related increase in expression of late-stage markers of autophagy, but it is unclear whether this contributes to the age-related reduction in soluble tau.

Even fewer studies have reported age-related changes in tau phosphorylation in nondemented individuals, let alone assess how these change with age. This is because the consensus view is that tau is not extensively phosphorylated in cortical regions of non-demented individuals who do not have overt pathology (41) with only a limited number of studies reporting some physiologically phosphorylated epitopes in non-AD brains $(42,43)$. In agreement with this, very little phosphorylation of tau was evident, at the PHF-1 epitope examined in this study, in any of the cortical brain tissues taken from non-demented individuals where there was a post-mortem delay. However, phosphorylation at this same site was clearly evident in resected cortical tissues taken from both young and old non-demented individuals, and there was a trend for this to increase with age, though this was not significant. 
One study published over 20 years ago made similar observations, showing that tau derived from biopsy non-AD brain tissue was more highly phosphorylated at several sites, thought to be primarily AD-specific, including PHF-1, AT8 and 12E8 and that phosphorylation at most of these sites was dramatically reduced if a post-mortem delay was artificially simulated, even if for 5-10 mins (14). We have previously shown that this is also true for endogenously phosphorylated rodent tau, where strong AT8 immunoreactivity is evident in hippocampal neurones (prominently localised to the somatodendritic compartment), which is reduced by nearly $75 \%$ when a post-mortem interval is simulated (17). As well as a lack of PM delay, one cannot exclude the impact of one other difference between the resected tissue and the PM tissue which is that in the former the patients underwent anaesthesia, which has been shown to increase tau phosphorylation $(84,85)$. However, we have previously demonstrated that in rodent brain, even in the absence of anaesthesia, tau is significantly more phosphorylated when tissue is processed quickly without PM delay compared to when it is processed with a PM delay (17) A post-mortem delay of several minutes is also created by default during trans-cardial perfusion fixation in rodent models of tauopathy, and this may also influence the phosphorylation status of any soluble tau species in those models.

Collectively, these findings and our own strongly suggest that soluble tau is more phosphorylated in cortical tissues from non-demented individuals than is generally reported, but that the phosphorylation status is significantly reduced by the postmortem delay. Phosphorylation status is adequately preserved in resected tissue, that though taken from individuals undergoing neurosurgery, is taken from brain regions that are physiologically and ultra-structurally normal as shown by us (in Supplementary Fig.1) and previously by others $(12,15)$. Studies in such tissues may be useful in future to assess if physiological phosphorylation of soluble tau increases with age, enhancing age-related risk of aggregation (44).

\section{Age-related changes in cytoskeletal integrity}

Since microtubule stabilisation is a key physiological function of tau, one may hypothesize that the age-related reduction in total tau may manifest in reduced cytoskeletal integrity. To assess the impact of age-related reduction of total tau, on the 
neuronal cytoskeleton, acetylation and tyrosination of alpha-tubulin, two posttranslational modifications that may indicate its stability, were probed $(18,45)$. Despite the significant reduction in total tau levels in the elderly cohorts compared to the younger cohorts, no change was observed in the acetylation or tyrosination levels of alpha-tubulin between the two groups. This implies that the loss of tau in the healthy control brains does not affect altered stability of microtubules with increasing age. It is possible that microtubule stability is only disrupted in the situation of tau hyperphosphorylation and profound neuronal loss that is observed in AD but not in aging control brains, or that age-related loss of tau is compensated for by an upregulation of other microtubule-associated proteins thereby preserving the neuronal cytoskeleton $(46,47)$. This result is in disagreement with that of Cash et al. (22), who reported an age-related reduction in cytoskeletal integrity in cortical biopsy samples from non-AD patients. However, their cortical samples were taken from more elderly individuals than ours, and their age range spanned 2 decades, ranging from 62-80 years, whereas ours spanned 5 decades ranging from 24-74 years.

\section{Age-related increase in markers of autophagy and age-related decline in total tau}

In order to examine the underlying biochemical pathways possibly responsible for the age-related reduction of total tau, we explored whether there were age-related changes in macroautophagy, a pathway implicated in tau turnover $(64,65)$. There is a lot of interest in protoeostatic pathways such as autophagy and the ubiquitinproteasome system, as they have been shown to regulate turnover of tau, and its accumulation in Tauopathies is postulated to arise due to an age-related functional decline in the efficiency of these pathways $(8,10,31,48,49)$. However, although there are numerous studies reporting autophagic induction in AD brains and comparing that to age-matched control brain $(50,51,9)$, there are only limited reports comparing markers of autophagy in brains of young and old non-AD subjects. Two studies that have examined this suggest that macroautophagy decreases with increasing age in normal brain, as shown by an age-related downregulation of several autophagy related genes (52) and Beclin 1, a protein essential for autophagy (53). The data presented here suggests that the situation is more complicated and one cannot 
necessarily assume that there is an age-related reduction in autophagy as the consensus view suggests.

We show that two markers of late-stage autophagy are increased with age, the ratio of LC3 II/I, a sensitive marker of macroautophagy (54), with a corresponding reduction in p62 (which is destroyed during autophagy), thus implying greater autophagy (55), whilst one marker of early stage autophagy, Beclin 1 is unchanged. Indeed increased autophagy with advancing age has been reported in other tissues $(57,58)$ and in choroid epithelial cells in brains of non-AD subjects (59). This is further supported by some studies of aging in experimental models, where markers of autophagy including LC3 II/I ratios and pro-autophagic regulators like BAG-3 are higher in brains of old animals when compared to young animals $(60,61)$. However, there are conflicting findings suggesting age-related decline in autophagy in other experimental models (11). Confusing the issue further, autophagy is believed to be upregulated with increasing age in long-lived animals and in healthy long-lived humans (62).

The findings presented here and the conflicting reports from other studies on physiological age-related changes in autophagic capacity, very few of which were conducted using material from human brain, collectively imply that the situation is complex and requires further investigation (62). Such investigations should also assess the cellular localisation of markers of autophagy, since some markers, like LC3-II, may appear to increase in conditions when autophagic flux is blocked, complicating interpretation of biochemical readouts (90). Only then could a consensus be reached as to whether autophagic capacity changes with age, especially in human brain, and whether this per se confers higher risk of neurodegenerative proteinopathies in the elderly.

Whilst the evidence for changes in autophagy with age is confusing, it has consistently been shown by many that autophagic clearance can regulate tau turnover $(63,64)$. The age-related decline in soluble tau that we report may therefore occur at least in part due to the age-related increase in autophagy suggested by the increased markers of autophagy that is also evident in these brains. However further studies will be needed to confirm this. Furthermore, since autophagy deficiency leads to agedependent neurodegeneration (65), it is possible that the lack of neurodegeneration 
in the brains of the older subjects in this study is a consequence of their healthy autophagic capacity. One may speculate that an age-related increase in effective autophagic capacity is a central component of healthy aging and protects healthy individuals from developing $A D$ as they age (Supplementary Fig. 4a blue line). However, deviation from this, for example if the soluble tau (or amyloid beta) load overwhelms the autophagic system, could trigger the onset of $A D$ in some individuals (Supplementary Fig. 4a, red line). Indeed, many studies have shown that macroautophagy is impaired in $A D$ brains (51) as well as in animal models of tauopathy (59). An alternative hypothesis, based on the consensus view discussed earlier, is that a reduction in autophagic capacity is evident in all individuals with increasing age, and this is the reason why some individuals might develop $A D$ (Supplmementary Fig. 4b). Though the latter does not explain why only some aged indiviudals go on to develop proteineopathy. Further studies, using additional markers of autophagy in a larger cohort are needed to distinguish between these two scenarios.

\section{Upregulation of autophagy rescues age-related tau phenotypes}

Our observation of increased markers of autophagy in aging human brains, evident in the face of decreased total tau levels and the absence of tau pathology, led us to hypothesize that induction of autophagy could ameliorate tau abnormalities in an agedependent manner in a Drosophila model. To test this hypothesis, we assessed the impact of upregulating autophagy in a Drosophila model of Tauopathy in which we have previously described age-related tau phenotypes (13). Drosophila is an ideal organism in which to test such hypotheses because it has been used for decades for genetically dissecting the pathways that underpin aging, autophagy and tau-mediated neurodegenerative diseases $(66,67,68,69)$. Indeed others have previously also shown that induction of autophagy in both rodent and Drosophila models of tauopathy reduces tau pathology and phenotypes $(59,63,83,91,92)$ but the impact of aging has not been investigated.

In agreement with these studies, our data show that co-expression of Atg1, a key autophagy protein $(70,71)$ ameliorates the age-dependent increase in tau phosphorylation and significantly improves the climbing ability of hTau ${ }^{0 N 3 R}$ expressing flies, a behaviour we have previously shown is associated with tau 
hyperphosphorylation (72). Interestingly, the beneficial effect of inducing autophagy was age-dependent, being more evident in older flies compared to younger flies. That increased autophagy is benefical for aging flies, as our data indicates, is supported by several other reports which demonstrate that both pharmacological and genetic upregulation of autophagy extends lifespan in invertebrate and vertebrate models of aging $(62,76,77)$, which in some cases is accompanied by suppression of brain aging and a reduction in total tau (78).

The consistent conclusion that can be drawn from all such studies is that robust autophagic capacity may be key for preventing the age-related accumulation and thus toxicity of aggregate-prone proteins such as tau, thus enabling healthy brain aging and protecting against neurodegeneration. Our studies also add to the growing weight of evidence suggesting that the activation of autophagy could be an important therapeutic target for the treatment of tauopathies $(31,49,93,94,95,96,97)$.

\section{Conclusions}

Our data highlight the importance of studying the effect of aging on the normal physiological turnover of aggregate-prone proteins like tau as well as the mechanistic pathways that might regulate this in the absence of disease. It is especially important to undertake such studies using normal human brain tissue to identify the impact of age-related changes without the confounding influence of underlying neurodegenerative disease. This is particularly relevant in understanding how aging confers risk of proteinopathies such as Alzheimer's disease.

\section{ACKNOWLEDGEMENTS}

We thank Dr. Anton Page for his electron microscopy training and advice and Ms. Hannah Warming for tissue collection and retrieval.

\section{AUTHOR CONTRIBUTIONS}

SC and MS contributed to the study design, performed the experiments and analysed the data, EC, ER, SG, EL, RR and MV performed the experiments under SC and MS's supervision. CMP performed the tissue collection and inflammation marker testing, PR did the electron microscopy, GV, PG and DB performed neurosurgery resection and 
DB was responsible for case identification, consent and theatre coordination. MVC coordinated the tissue collection, processing and electrophysiological analysis. AM and CGP contributed to the overall vision and planning of this study as well as critical writing/edits of the manuscript.

\section{FUNDING}

This work was funded by the Kerkut trust and Alzheimer's Research UK.

\section{AVAILABILITY OF DATA AND MATERIALS}

The datasets analysed for the current study will be available from the corresponding author on reasonable request.

\section{ETHICS APPROVAL AND CONSENT TO PARTICIPATE}

The use of human tissue complied with the Human Tissue Act (Southampton Research Biorepository study reference number: SRB002/14). Informed consent was obtained from all patients to use surgically resected tissue not required for diagnostic purposes.

\section{CONSENT FOR PUBLICATION}

All the authors have consented.

\section{CONFLICT OF INTEREST}

The authors declare conflict of interest with Professor Karen Duff (UK DRI), Professor Wendy Noble (King's College, London) and Professor Diane Hanger (King's College, London)

\section{REFERENCES}

1. Yankner, B.A., Lu, T. and Loerch, P. (2008). "The aging brain." Annu Rev Pathol 3: 41-66.

2. Bishop, N.A., Lu, T. and Yankner, B.A. (2010). "Neural mechanisms of ageing and cognitive decline." Nature 464(7288): 529-535. 
3. Bancher, C., Braak, H., Fischer, P. and Jellinger, K.A. (1993). "Neuropathological Staging of Alzheimer Lesions and Intellectual Status in Alzheimer's and Parkinson's Disease Patients". Neurosci Lett Nov 12;162(12):179-82.

4. Serrano-Pozo, A., Frosch, M.P., Masliah. E. and Hyman. B.T. (2011). "Neuropathological alterations in Alzheimer disease." Cold Spring Harb Perspect Med 1(1): a006189.

5. Xia, X., Jiang, Q., McDermott, J. and Han, J.J. (2018). "Aging and Alzheimer's disease: Comparison and associations from molecular to system level." Aging Cell 17(5): e12802.

6. Vemuri, P. (2018). "'Exceptional brain aging" without Alzheimer's disease: triggers, accelerators, and the net sum game." Alzheimers Res Ther 10(1): 53.

7. Peters, R. (2006). "Ageing and the brain." Postgrad Med J 82(964): 84-88.

8. Kaushik, S. and Cuervo, A.M. (2015). "Proteostasis and aging." Nat Med 21(12): 1406-1415.

9. Bar-Yosef, T., Damri, O. and Agam, G. (2019). "Dual Role of Autophagy in Diseases of the Central Nervous System." Front Cell Neurosci 13: 196.

10.Scrivo, A., Bourdenx, M., Pampliega, O. and Cuervo, A.M. (2018). "Selective autophagy as a potential therapeutic target for neurodegenerative disorders." Lancet Neurol 17(9): 802-815.

11. Loeffler, D.A. (2019). "Influence of Normal Aging on Brain Autophagy: A Complex Scenario." Front Aging Neurosci 11: 49.

12. Pegasiou, C.M., Zolnourian, A., Gomez-Nicola, D., Deinhardt, K., Nicoll, J.A.R., Ahmed, A.I., Vajramani, G., Grundy, P., Verhoog, M.B., Mansvelder, H.D., Perry, V.H., Bulters, D. and Vargas-Caballero, M. (2020). "AgeDependent Changes in Synaptic NMDA Receptor Composition in Adult Human Cortical Neurons." Cereb Cortex.

13. Sealey, M.A., Vourkou, E., Cowan, C.M., Bossing, T., Quraishe, S., Grammenoudi, S., Skoulakis, E.M.C. and Mudher, A. (2017). "Distinct phenotypes of three-repeat and four-repeat human tau in a transgenic model of tauopathy." Neurobiol Dis 105: 74-83.

14. Seubert, P., Mawal-Dewan, M., Barbour, R., Jakes, R., Goedert, M., Johnson, G.V., Litersky, J.M., Schenk, D., Lieberburg, I., Trojanowski, J.Q. et al. (1995). "Detection of phosphorylated Ser262 in fetal tau, adult tau, and paired helical filament tau." J Biol Chem 270(32): 18917-18922.

15. Schneider, A., Biernat, J., von Bergen, M., Mandelkow, E. and Mandelkow, E.M. (1999). "Phosphorylation that detaches tau protein from microtubules 
(Ser262, Ser214) also protects it against aggregation into Alzheimer paired helical filaments." Biochemistry 38(12): 3549-3558.

16. Matsuo, E.S., Shin, R.W., Billingsley, M.L., Van deVoorde, A., O'Connor, M., Trojanowski, J.Q. and Lee, V.M. (1994). "Biopsy-derived adult human brain tau is phosphorylated at many of the same sites as Alzheimer's disease paired helical filament tau." Neuron 13(4): 989-1002.

17. Mudher, A.K., Woolley, S.T., Perry, V.H. and Greene, J.R. (1999). "Induction of hyperphosphorylated tau in living slices of rat hippocampal formation and subsequent detection using an ELISA." J Neurosci Methods 88(1): 15-25.

18. Buee, L., Bussiere, T., Buee-Scherrer, V., Delacourte, A. and Hof, P.R. (2000). "Tau protein isoforms, phosphorylation and role in neurodegenerative disorders." Brain Res Brain Res Rev 33(1): 95-130.

19.Breuzard, G., Hubert, P., Nouar, R., De Bessa, T., Devred, F., Barbier, P., Sturgis, J.N. and Peyrot, V. (2013). "Molecular mechanisms of Tau binding to microtubules and its role in microtubule dynamics in live cells." J Cell Sci 126(Pt 13): 2810-2819.

20.Cash, A.D., Aliev, G., Siedlak, S.L., Nunomura, A., Fujioka, H., Zhu, X., Raina, A.K., Vinters, H.V., Tabaton, M., Johnson, A.B., M. Paula-Barbosa, Avila, J., Jones, P.K., Castellani, R.J., Smith, M.A. and Perry, G. (2003). "Microtubule reduction in Alzheimer's disease and aging is independent of tau filament formation." Am J Pathol 162(5): 1623-1627.

21. Brandt, R. and Bakota, L. (2017). "Microtubule dynamics and the neurodegenerative triad of Alzheimer's disease: The hidden connection." $\underline{\mathrm{J}}$ Neurochem 143(4): 409-417.

22. Hammond, J.W., Cai, D. and Verhey, K.J. (2008). "Tubulin modifications and their cellular functions." Curr Opin Cell Biol 20(1): 71-76.

23. Janke, C. and Montagnac, G. (2017). "Causes and Consequences of Microtubule Acetylation." Curr Biol 27(23): R1287-R1292.

24. Liu, W.J., Ye, L., Huang, W.F., Guo, L.J., Xu, Z.G., Wu, H.L., Yang, C. and Liu, H.F. (2016). "p62 links the autophagy pathway and the ubiqutin-proteasome system upon ubiquitinated protein degradation." Cell Mol Biol Lett 21: 29.

25. Tanida, I., Ueno, T. and Kominami, E. (2008). "LC3 and Autophagy." Methods Mol Biol 445: 77-88.

26. Pickford, F., Masliah, E., Britschgi, M., Lucin, K., Narasimhan, R., Jaeger, P.A., Small, S., Spencer, B., Rockenstein, E., Levine, B. and Wyss-Coray, T. (2008). "The autophagy-related protein beclin 1 shows reduced expression in early Alzheimer disease and regulates amyloid beta accumulation in mice." $\mathrm{J}$ Clin Invest 118(6): 2190-2199. 
27. Scott, R.C., Juhasz, G. and Neufeld, T.P. (2007). "Direct induction of autophagy by Atg1 inhibits cell growth and induces apoptotic cell death." Curr Biol 17(1): $1-11$.

28. Kijak, E. and Pyza, E. (2017). "TOR signaling pathway and autophagy are involved in the regulation of circadian rhythms in behavior and plasticity of L2 interneurons in the brain of Drosophila melanogaster." PLoS One 12(2): e0171848.

29. Guerreiro, R. and Bras, J. (2015). "The age factor in Alzheimer's disease." Genome Med 7: 106.

30.Edwards lii, G.A., Gamez, N., Escobedo, G., Calderon, O. and MorenoGonzalez, I. (2019). "Modifiable Risk Factors for Alzheimer's Disease." Front Aging Neurosci 11: 146.

31. Limanaqi, F., Biagioni, F., Gambardella, S., Familiari, P., Frati, A. and Fornai, F. (2020). "Promiscuous Roles of Autophagy and Proteasome in Neurodegenerative Proteinopathies." Int J Mol Sci 21(8).

32. Braak, H., Braak, E. and Bohl, J. (1993). "Staging of Alzheimer-related cortical destruction." Eur Neurol 33(6):403-8.

33. Arriagada, P.V., Growdon, J.H., Hedley-Whyte, E.T. and Hyman, B.T. (1992). "Neurofibrillary tangles but not senile plaques parallel duration and severity of Alzheimer's disease." Neurology 42(3 Pt 1): 631-639.

34. Tanprasertsuk, J., Johnson, E.J., Johnson, M.A., Poon, L.W., Nelson, P.T., Davey, A., Martin, P., Barbey, A.K., Barger, K., Wang, X.D. and Scott, T.M. (2019). "Clinico-Neuropathological Findings in the Oldest Old from the Georgia Centenarian Study." J Alzheimers Dis 70(1): 35-49.

35. Mullen, R.J., Buck, C.R. and Smith, A.M. (1992). "NeuN, a neuronal specific nuclear protein in vertebrates." Development 116(1): 201-211.

36. Mukaetova-Ladinska, E.B., Harrington, C.R., Roth, M. and Wischik, C.M. (1996). "Alterations in tau protein metabolism during normal aging." Dementia 7(2): 95-103.

37. Bouras, C., Hof, P.R., Giannakopoulos, P., Michel, J.P. and Morrison, J.H. (1994). "Regional distribution of neurofibrillary tangles and senile plaques in the cerebral cortex of elderly patients: a quantitative evaluation of a one-year autopsy population from a geriatric hospital." Cereb Cortex 4(2): 138-150.

38. Lowe, V.J., Wiste, H.J., Senjem, M.L., Weigand, S.D., Therneau, T.M., Boeve, B.F., Josephs, K.A., Fang, P., Pandey, M.K., Murray, M.E., Kantarci, K., Jones, D.T., Vemuri, P., Graff-Radford, J., Schwarz, C.G., Machulda, M.M., Mielke, M.M., Roberts, R.O., Knopman, D.S., Petersen, R.C. and Jack, Jr, C.R. (2018). "Widespread brain tau and its association with ageing, Braak stage and Alzheimer's dementia." Brain 141(1): 271-287. 
39. Dickey, C., Kraft, C., Jinwal, U., Koren, J., Johnson, A., Anderson, L., Lebson, L., Lee, D., Dickson, D., de Silva, R., Binder, L.I., Morgan, D. and Lewis, J. (2009). "Aging analysis reveals slowed tau turnover and enhanced stress response in a mouse model of tauopathy." Am J Pathol 174(1): 228-238.

40. Metaxas, A., Thygesen, C., Kempf, S.J., Anzalone, M., Vaitheeswaran, R., Petersen, S., Landau, A.M., Audrain, H., Teeling, J.L., Darvesh, S., Brooks, D.J., Larsen, M.R. and Finsen, B. (2019). "Ageing and amyloidosis underlie the molecular and pathological alterations of tau in a mouse model of familial Alzheimer's disease." Sci Rep 9(1): 15758.

41. Braak, H., Thal, D.R., Ghebremedhin, E. and Del Tredici, K. (2011). "Stages of the pathologic process in Alzheimer disease: age categories from 1 to 100 years." $\underline{\mathrm{J}}$ Neuropathol Exp Neurol 70(11): 960-969.

42. Ercan-Herbst, E., Ehrig, J., Schondorf, D.C., Behrendt, A., Klaus, B., Gomez Ramos, B., Prat Oriol, N., Weber, C. and Ehrnhoefer, D.E. (2019). "A posttranslational modification signature defines changes in soluble tau correlating with oligomerization in early stage Alzheimer's disease brain." Acta Neuropathol Commun 7(1): 192.

43. Hanger, D.P., Byers, H.L., Wray, S., Leung, K.Y., Saxton, M.J., Seereeram, A., Reynolds, C.H., Ward, M.A. and Anderton, B.H. (2007). "Novel phosphorylation sites in tau from Alzheimer brain support a role for casein kinase 1 in disease pathogenesis." J Biol Chem 282(32): 23645-23654.

44. Vargas-Caballero, M., Willaime-Morawek, S., Gomez-Nicola, D., Perry, V.H., Bulters, D. and Mudher, A. (2016). "The use of human neurons for novel drug discovery in dementia research." Expert Opin Drug Discov 11(4): 355-367.

45. Wloga, D., Joachimiak, E. and Fabczak, H. (2017). "Tubulin Post-Translational Modifications and Microtubule Dynamics." Int J Mol Sci 18(10).

46.Zhang, F., Su, B., Wang, C., Siedlak, S.L., Mondragon-Rodriguez, S., Lee, H.G., Wang, X., Perry, G. and Zhu, X. (2015). "Posttranslational modifications of alpha-tubulin in alzheimer disease." Transl Neurodegener 4: 9.

47. Hempen, B. and Brion, J.P. (1996). "Reduction of acetylated alpha-tubulin immunoreactivity in neurofibrillary tangle-bearing neurons in Alzheimer's disease." J Neuropathol Exp Neurol 55(9): 964-972.

48. Mputhia, Z., Hone, E., Tripathi, T., Sargeant, T., Martins, R. and Bharadwaj, P. (2019). "Autophagy Modulation as a Treatment of Amyloid Diseases." Molecules 24(18).

49. Djajadikerta, A., Keshri, S., Pavel, M., Prestil, R., Ryan, L. and Rubinsztein, D.C. (2020). "Autophagy Induction as a Therapeutic Strategy for Neurodegenerative Diseases." J Mol Biol 432(8): 2799-2821. 
50.Piras, A., Collin, L., Gruninger, F., Graff, C. and Ronnback, A. (2016). "Autophagic and lysosomal defects in human tauopathies: analysis of postmortem brain from patients with familial Alzheimer disease, corticobasal degeneration and progressive supranuclear palsy." Acta Neuropathol Commun 4: 22.

51. Nixon, R.A., Wegiel, J., Kumar, A., Yu, W.H., Peterhoff, C., Cataldo, A. and Cuervo, A.M. (2005). "Extensive involvement of autophagy in Alzheimer disease: an immuno-electron microscopy study." J Neuropathol Exp Neurol 64(2): 113-122.

52. Lipinski, M.M., Zheng, B., Lu, T., Yan, Z., Py, B.F., Ng, A., Xavier, R.J., Li, C., Yankner, B.A., Scherzer, C.R. and Yuan, J. (2010). "Genome-wide analysis reveals mechanisms modulating autophagy in normal brain aging and in Alzheimer's disease." Proc Natl Acad Sci U S A 107(32): 14164-14169.

53. Shibata, M., Lu, T., Furuya, T., Degterev, A., Mizushima, N., Yoshimori, T., MacDonald, M., Yankner, B. and Yuan, J. (2006). "Regulation of intracellular accumulation of mutant Huntingtin by Beclin 1." J Biol Chem 281(20): 1447414485.

54. Karim, M.R., Kanazawa, T., Daigaku, Y., Fujimura, S., Miotto, G. and Kadowaki, M. (2007). "Cytosolic LC3 ratio as a sensitive index of macroautophagy in isolated rat hepatocytes and H4-II-E cells." Autophagy 3(6): 553-560.

55. Klionsky, D.J., Abdalla, F.C., Abeliovitch, H., Abraham, R.T. et al (2012). "Guidelines for the Use and Interpretation of Assays for Monitoring Autophagy" Autophagy 8(4):445-544.

56. Grimm, A. and Eckert, A. (2017). "Brain aging and neurodegeneration: from a mitochondrial point of view." J Neurochem 143(4): 418-431.

57. Ward, W. and Richardson, A. (1991). "Effect of age on liver protein synthesis and degradation." Hepatology 14(5): 935-948.

58. Ward, W.F. (2002). "Protein degradation in the aging organism." Prog Mol Subcell Biol 29: 35-42.

59.Bakhoum, M.F., Bakhoum, C.Y., Ding, Z., Carlton, S.M., Campbell, G.A. and Jackson, G.R. (2014). "Evidence for autophagic gridlock in aging and neurodegeneration." Transl Res 164(1): 1-12.

60. Gamerdinger, M., Hajieva, P., Kaya, A.M., Wolfrum, U., Hartl, F.U. and Behl, C. (2009). "Protein quality control during aging involves recruitment of the macroautophagy pathway by BAG3." EMBO J 28(7): 889-901.

61. De Biase, D., Costagliola, A., Pagano, T.B., Piegari, G., Wojcik, S., Dziewiatkowski, J., Grieco, E., Mattace Raso, G., Russo, V., Papparella, S. and Paciello, O. (2017). "Amyloid precursor protein, lipofuscin accumulation and expression of autophagy markers in aged bovine brain." BMC Vet Res 13(1): 102 
62. Nakamura, S. and Yoshimori, T. (2018). "Autophagy and Longevity." Mol Cells 41(1): 65-72.

63.Berger, Z., Ravikumar, B., Menzies, F.M., Oroz, L.G., Underwood, B.R., Pangalos, M.N., Schmitt, I., Wullner, U., Evert, B.O., O'Kane, C.J. and Rubinsztein, D.C. (2006). "Rapamycin alleviates toxicity of different aggregateprone proteins." Hum Mol Genet 15(3): 433-442.

64. Caballero, B., Wang, Y., Diaz, A., Tasset, I., Juste, Y.R., Stiller, B., Mandelkow, E.M., Mandelkow, E. and Cuervo, A.M. (2018). "Interplay of pathogenic forms of human tau with different autophagic pathways." Aging Cell 17(1).

65. Inoue, K., Rispoli, J., Kaphzan, H., Klann, E., Chen, E.I., Kim, J., Komatsu, M. and Abeliovich, A. (2012). "Macroautophagy deficiency mediates agedependent neurodegeneration through a phospho-tau pathway." Mol Neurodegener 7: 48.

66. Jackson, G. R., Wiedau-Pazos, M., Sang, T.K., Wagle, N., Brown, C.A., Massachi, S. and Geschwind, D.H. (2002). "Human wild-type tau interacts with wingless pathway components and produces neurofibrillary pathology in Drosophila." Neuron 34(4): 509-519.

67. Chatterjee, S., Sang, T.K., Lawless, G.M. and Jackson, G.R. (2009). "Dissociation of tau toxicity and phosphorylation: role of GSK-3beta, MARK and Cdk5 in a Drosophila model." Hum Mol Genet 18(1): 164-177.

68. Shulman, J. M., Imboywa, S., Giagtzoglou, N., Powers, M.P., Hu, Y., Devenport, D., Chipendo, P., Chibnik, L.B., Diamond, A., Perrimon, N., Brown, N.H., De Jager, P.L. and Feany, M.B. (2014). "Functional screening in Drosophila identifies Alzheimer's disease susceptibility genes and implicates Tau-mediated mechanisms." Hum Mol Genet 23(4): 870-877.

69. Bjedov, I. and Partridge, L. (2011). "A longer and healthier life with TOR downregulation: genetics and drugs." Biochem Soc Trans 39(2): 460-465.

70.Wang, B. and Kundu, M. (2017). "Canonical and noncanonical functions of ULK/Atg1." Curr Opin Cell Biol 45: 47-54.

71. Ling, D. and Salvaterra, P.M. (2009). "A central role for autophagy in Alzheimertype neurodegeneration." Autophagy 5(5): 738-740.

72. Folwell, J., Cowan, C.M., Ubhi, K.K., Shiabh, H., Newman, T.A., Shepherd, D. and Mudher, A. (2010). "Abeta exacerbates the neuronal dysfunction caused by human tau expression in a Drosophila model of Alzheimer's disease." Exp Neurol 223(2): 401-409.

73. McPhee, C. K. and Baehrecke, E.H. (2009). "Autophagy in Drosophila melanogaster." Biochim Biophys Acta 1793(9): 1452-1460. 
74.Lopez, A., Lee, S.E., Wojta, K., Ramos, E.M., Klein, E., Chen, J., Boxer, A.L., Gorno-Tempini, M.L., Geschwind, D.H., Schlotawa, L., Ogryzko, N.V., Bigio, E.H., Rogalski, E., Weintraub, S., Mesulam, M.M., C. Tauopathy Genetics, Fleming, A., Coppola, G., Miller, B.L. and Rubinsztein, D.C. (2017). "A152T tau allele causes neurodegeneration that can be ameliorated in a zebrafish model by autophagy induction." Brain 140(4): 1128-1146.

75.Schaeffer, V., Lavenir, I., Ozcelik, S., Tolnay, M., Winkler, D.T. and Goedert, M. (2012). "Stimulation of autophagy reduces neurodegeneration in a mouse model of human tauopathy." Brain 135(Pt 7): 2169-2177.

76. Caccamo, A., Magri, A., Medina, D.X., Wisely, E.V., Lopez-Aranda, M.F., Silva, A.J. and Oddo, S. (2013). "mTOR regulates tau phosphorylation and degradation: implications for Alzheimer's disease and other tauopathies." Aging Cell 12(3): 370-380.

77.Bjedov, I., Toivonen, J.M., Kerr, F., Slack, C., Jacobson, J., Foley, A. and Partridge, L. (2010). "Mechanisms of life span extension by rapamycin in the fruit fly Drosophila melanogaster." Cell Metab 11(1): 35-46.

78. Kolosova, N. G., Vitovtov, A.O., Muraleva, N.A., Akulov, A.E., Stefanova, N.A. and Blagosklonny, M.V. (2013). "Rapamycin suppresses brain aging in senescence-accelerated OXYS rats." Aging (Albany NY) 5(6): 474-484.

79.Verhoog, M. B., Goriounova, N.A., Obermayer, J., Stroeder, J., Hjorth, J.J., Testa-Silva, G., Baayen, J.C., de Kock, C.P., Meredith, R.M. and Mansvelder, H.D. (2013). "Mechanisms underlying the rules for associative plasticity at adult human neocortical synapses." J Neurosci 33(43): 17197-17208.

80. Dolan, P. J. and Johnson, G.V. (2010). "A caspase cleaved form of tau is preferentially degraded through the autophagy pathway." J Biol Chem 285(29): 21978-21987.

81. Wang, A. L., Lukas, T.J., Yuan, M., Du, N., Tso, M.O. and Neufeld, A.H. (2009). "Autophagy, exosomes and drusen formation in age-related macular degeneration." Autophagy 5(4): 563-564.

82. Shibuya, Y., Niu, Z., Bryleva, E.Y., Harris, B.T., Murphy, S.R., Kheirollah, A., Bowen, Z.D., Chang, C.C.Y. and Chang, T.Y. (2015). "Acyl-coenzyme A:cholesterol acyltransferase 1 blockage enhances autophagy in the neurons of triple transgenic Alzheimer's disease mouse and reduces human P301L-tau content at the presymptomatic stage." Neurobiol Aging 36(7): 2248-2259.

83. Galasso, A., Cameron, C.S., Frenguelli, B.G. and Moffat, K.G. (2017). "An AMPK-dependent regulatory pathway in tau-mediated toxicity." Biol Open 6(10): 1434-1444.

84. Planel, E., Richter, K.E., Nolan, C.E., Finley, J.E., Liu, L., Wen, Y., Krishnamurthy, P., Herman, M., Wang, L., Schachter, J.B., Nelson, R.B., Lau, L.F. and Duff, K.E. (2007). "Anesthesia leads to tau hyperphosphorylation 
through inhibition of phosphatase activity by hypothermia." $\underline{\mathrm{J} \text { Neurosci }}$ 27(12): 3090-3097.

85. Eckenhoff, R. G. and Planel, E. (2012). "Postoperative cognitive decline: where art tau?" Anesthesiology 116(4): 751-752

86. Mudher, A. K., Woolley, S.T., Perry, V.H. and J. R. Greene (1999). "Induction of hyperphosphorylated tau in living slices of rat hippocampal formation and subsequent detection using an ELISA." J Neurosci Methods 88(1): 15-25.

87. Cowan, C. M., Bossing, T., Page, A., Shepherd, D. and Mudher, A. (2010). "Soluble hyper-phosphorylated tau causes microtubule breakdown and functionally compromises normal tau in vivo." Acta Neuropathol 120(5): 593604.

88. Ubhi, K. K., Shaibah, H., Newman, T. A., Shepherd, D. and Mudher, A. (2007). "A comparison of the neuronal dysfunction caused by Drosophila tau and human tau in a Drosophila model of tauopathies." Invert Neurosci 7(3): 165171.

89. Nag, T.C, Kathpalia, K. P. and Wadhwa, S. (2020). "Microtubule alterations may destabilize photoreceptor integrity: Age-related microtubule changes and pattern of expression of MAP-2, Tau and hyperphosphorylated Tau in aging human photoreceptor cells." Exp Eye Res 198: 1-15

90. Klionsky, D. J., Abdel-Aziz, A. K., Abdelfatah, S., Abdellatif, M., Abdoli, A., Abel, S., Abeliovich, H., Abildgaard, M. H., Abudu, Y. P., Acevedo-Arozena, A., I Adamopoulos et al. (2021). "Guidelines for the use and interpretation of assays for monitoring autophagy (4th edition)(1)." Autophagy 17(1): 1-382.

91. Caccamo, A., Magri, A., Medina, D. X., Wisely, E. V., Lopez-Aranda, M. F., Silva, A. J. and Oddo, S. (2013). "mTOR regulates tau phosphorylation and degradation: implications for Alzheimer's disease and other tauopathies." Aging Cell 12(3): 370-380.

92. Schaeffer, V. and Goedert, M. (2012). "Stimulation of autophagy is neuroprotective in a mouse model of human tauopathy." Autophagy 8(11): 1686-1687.

93. Wahl, D., Solon-Biet, S. M., Wang, Q. P., Wali, J. A., Pulpitel, T., Clark, X., Raubenheimer, D., Senior, A. M., Sinclair, D. A., Cooney, G. J., de Cabo, R., Cogger, V. C., Simpson, S. J. and Le Couteur, D. G. (2018). "Comparing the Effects of Low-Protein and High-Carbohydrate Diets and Caloric Restriction on Brain Aging in Mice." Cell Rep 25(8): 2234-2243 e2236.

94.Wahl, D., Coogan, S. C., Solon-Biet, S. M., de Cabo, R., Haran, J. B., Raubenheimer, D., Cogger, V. C., Mattson, M. P., Simpson, S .J. and Le Couteur, D. G. (2017). "Cognitive and behavioral evaluation of nutritional interventions in rodent models of brain aging and dementia." Clin Interv Aging 12: 1419-1428. 
95.Wahl, D., Cogger, V. C., Solon-Biet, S. M., Waern, R. V., Gokarn, R., Pulpitel, T., Cabo, R., Mattson, M. P., Raubenheimer, D., Simpson, S. L. and Le Couteur, D. G. (2016). "Nutritional strategies to optimise cognitive function in the aging brain." Ageing Res Rev 31: 80-92.

96. Wahl, D., Solon-Biet, S. M., Cogger, V. C., Fontana, L., Simpson, S. J., Le Couteur, D. G. and Ribeiro, R. V. (2019). "Aging, lifestyle and dementia." Neurobiol Dis 130: 104481.

97.Uddin, M. S., Stachowiak, A., Mamun, A. A., Tzvetkov, N. T., Takeda, S., Atanasov, A. G., Bergantin, L. B., Abdel-Daim, M. M. and Stankiewicz, A. M. (2018). "Autophagy and Alzheimer's Disease: From Molecular Mechanisms to Therapeutic Implications." Front Aging Neurosci 10: 04.

98. Singh-Manoux, A., Kivimaki, M., Glymour, M.M., Elbaz, A., Berr, C., Ebmeier, K. P., Ferrie, J. E. and Dugravot, A. (2012). "Timing of onset of cognitive decline: results from Whitehall II prospective cohort study." BMJ 344: d7622.

\section{Figure Legends}

Figure 1. Total tau levels are significantly decreased in the healthy older brains compared to the younger brains. Representative western blot images for total tau, PHF1 and Actin in post-mortem brains (A i) and quantification of total tau normalized to Actin (A iii). Representative western blot image for NeuN and Actin in post-mortem brains (A ii) and quantification of NeuN normalized to Actin (A iii). Representative western blot images for total tau, PHF1 and Actin in resected tissues (B i) and quantification of total tau and PHF1/total tau normalized to Actin (B ii and iii). In postmortem samples $n=6$ (older brains $70-74$ years), $n=6$ (younger brains $20-33$ years), in resected tissue samples $n=13$ (older brains 50-70 years and younger brains 19-42 years). ${ }^{* \star *} p<0.0001,{ }^{*} p<0.05$ by two-tailed unpaired t test. Data represent mean \pm SEM ( $A$ iii and B ii). An increased level of PHF1 immunoreactivity was observed in older brains of resected tissues although it was not significant (B iii).

Figure 2. The levels of total $\alpha$-tubulin and its post-translational modifications are not altered with age in post-mortem brains. Representative western blot images for acetylated $\alpha$-tubulin, total $\alpha$-tubulin and GAPDH in post-mortem brains (A i) and quantification of actetylated $\alpha$-tubulin relative to total $\alpha$-tubulin normalized to GAPDH (A ii). Representative western blot images for tyrosinated $\alpha$-tubulin, total $\alpha$-tubulin and GAPDH in post-mortem brains $(\mathrm{B}$ i) and quantification of tyrosinated $\alpha$-tubulin relative to total $\alpha$-Tubulin normalized to GAPDH (B ii). In post-mortem samples $n=6$ (older brains) and $n=6$ (younger brains). $p$ values are not significant by two-tailed unpaired $t$ test. Data represent mean \pm SEM ( $A$ ii and $B$ ii). 
Figure 3. Autophagy is significantly increased in the healthy older brains compared to the younger brains in post-mortem tissues. Representative western blot images for p62 and Actin in post-mortem brains ( $\mathrm{A}$ i) and quantification of p62 normalized to Actin (A ii). Representative western blot images for LC3 and Actin in post-mortem brains (B i) and quantification of LC3-II/LC3-I normalized to Actin (B ii) and LC3-II normalised to Actin (B iii). In post-mortem samples $n=7$ (older brains), $n=6$ (younger brains). ${ }^{*} p<0.05$, by two-tailed unpaired $t$ test. Data represent mean \pm SEM (A ii and $B$ ii).

Figure 4: Early autophagy gene Beclin 1 is not significantly increased in the older brains compared to the younger brains in post-mortem tissues. Representative western blot images for Beclin 1 and Actin in post-mortem brains (i) and quantification of Beclin 1 normalized to Actin (ii). In post-mortem samples $n=7$ (older brains), $n=6$ (younger brains). $p$ values are not significant by two-tailed unpaired $\mathrm{t}$ test. Data represent mean \pm SEM.

Figure 5. Upregulation of autophagy decreases the age-related accumulation of hyperphosphorylated tau and ameliorates tau-induced locomotor defects in human Tau (ON3R) expressing transgenic flies. Pan-neuronal expression of human ON3R tau significantly increases the age-dependent accumulation of hyperphosphorylated tau that is restricted by coexpression of autophagy marker Atg1. Representative western blot images for PHF1, total tau and Actin (A i) and quantification of PHF1 relative to total tau normalized to Actin ( $A$ ii) in htau ${ }^{0 N 3 R}$ and htau ${ }^{0 N 3 R} /$ Atg1 overexpressing Drosophila models respectively. ${ }^{*} \mathrm{p}<0.01$ by one-way ANOVA with Bonferroni's correction. Data represent mean \pm S.E.M. Expression of 03NR human tau pan-neuronally in adult flies induces locomotor deficits that are rescued by coexpression of Atg1 (B) Comparison of the climbing ability with age over a period of 4 weeks for $\mathrm{hTau}{ }^{\mathrm{ON} 3 \mathrm{R}}$, Atg1 and $\mathrm{hTau}{ }^{\mathrm{ON} 3 \mathrm{R}} / \operatorname{Atg} 1$ transgenics $(\mathrm{n}=50)$. (2 way ANOVA; $\left.{ }^{*} p<0.05,{ }^{* *} p<0.001,{ }^{* * * *} p<0.0001\right)$. Error bars are plotted as \pm S.E.M. Genotypes: $h \mathrm{hTau}^{0 \mathrm{~N} 3 \mathrm{R}}=\left\{\mathrm{w} ;\right.$ Elav-Geneswitch/UAS-htau $\left.{ }^{0 \mathrm{~N} 3 \mathrm{R}}\right\}, \quad \operatorname{Atg} 1=\{\mathrm{w} ;$ ElavGeneswitch/+; UAS-Atg1/+ $\}$, hTau ${ }^{0 N 3 R / A t g 1}=\left\{w ;\right.$ Elav-Geneswitch /UAS-htau ${ }^{\text {ON3R; }}$ UAS-Atg1/+\}, on an OreR background.

Table 1. Case study details of the human post-mortem brain and surgically resected tissues. Post-mortem brain tissues were obtained from the Sudden Death Brain Bank and divided into young (20 to 33 years) and old (70 to 74 years) cohorts. There was no significant difference in the post-mortem intervals between the young and old cohorts $(p=0.48)$. Age-matched resected tissues (19 to 70 years) were collected from the Southampton General Hospital. Neuropathological abnormalities were found in cases 0011 and 0020 but no neurodegenerative changes were detected in any of the human tissues. Note: F, female; M, male; DNET, dysembryoplastic neuroepithelial tumor. 
bioRxiv preprint doi: https://doi.org/10.1101/2021.08.21.456385; this version posted August 21, 2021. The copyright holder for this preprint (which was not certified by peer review) is the author/funder. All rights reserved. No reuse allowed without permission. 


\section{A Postmortem Brains}
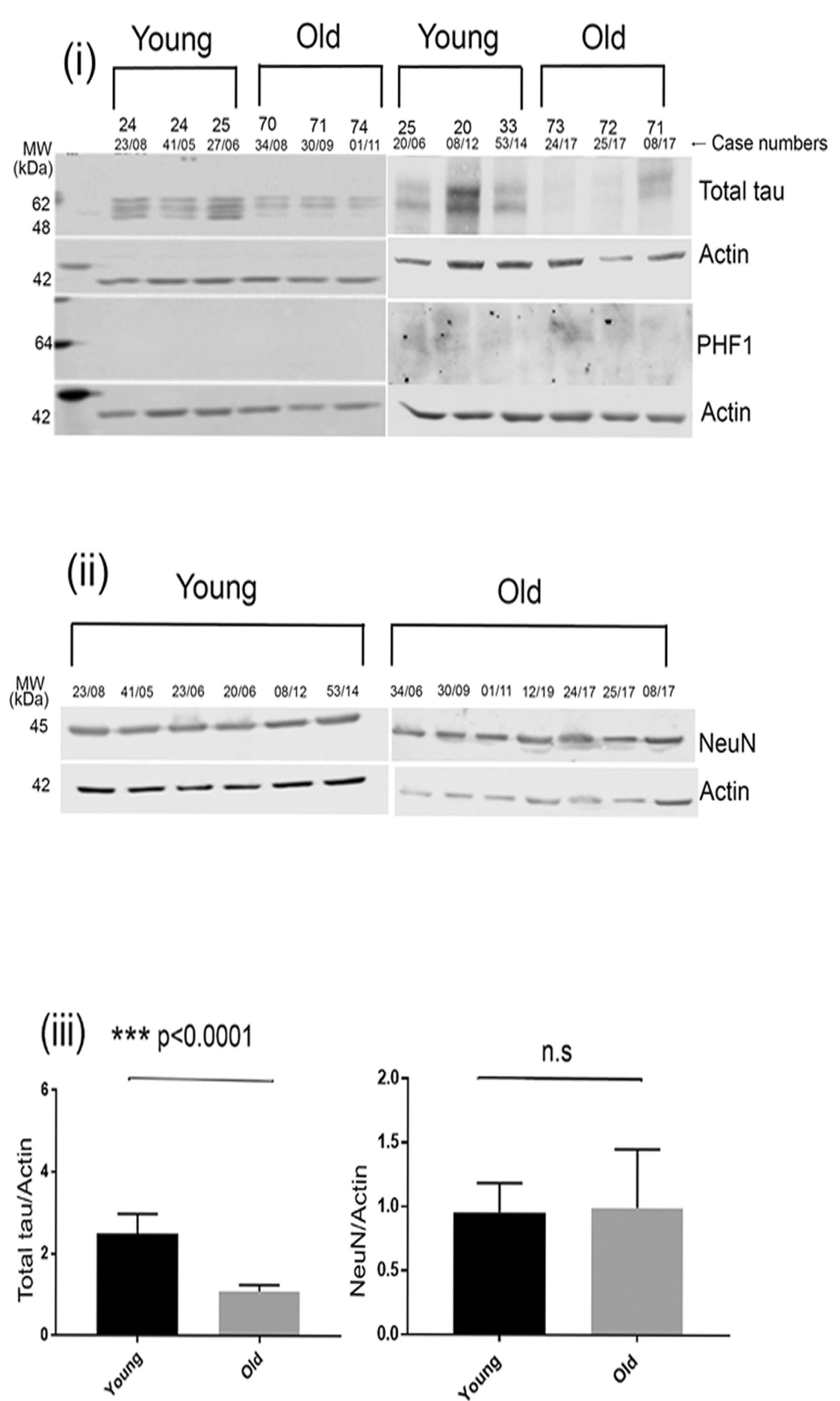

Age/years

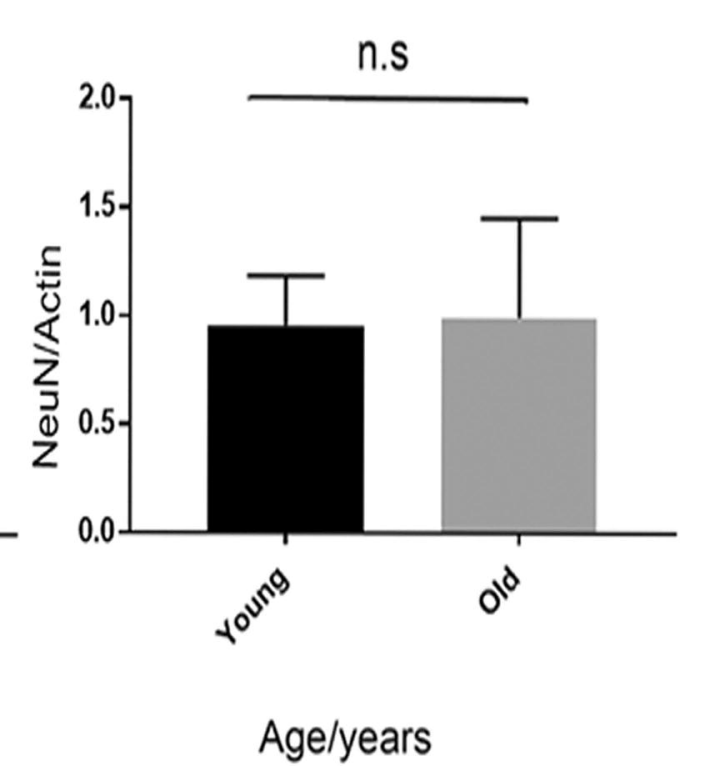

\section{B Resected Tissues}

(i) Young $n$ Old $n$ Young

$\begin{array}{llllllllllllllllllllll} & 27 & 29 & 35 & 36 & 38 & 42 & 50 & 62 & 19 & 25 & 32 & 35 & 36 & 38 & 42 & 50 & 55 & 62 & 69 & 70 & \\ M W & 26 & 32 & 23 & 16 & 28 & 11 & 24 & 25 & -19 & 32 & 14 & 23 & 16 & 28 & 11 & 24 & 12 & 17 & 13 & 20 & \text { - Case numbers }\end{array}$

(KDa)
62
48

42 -
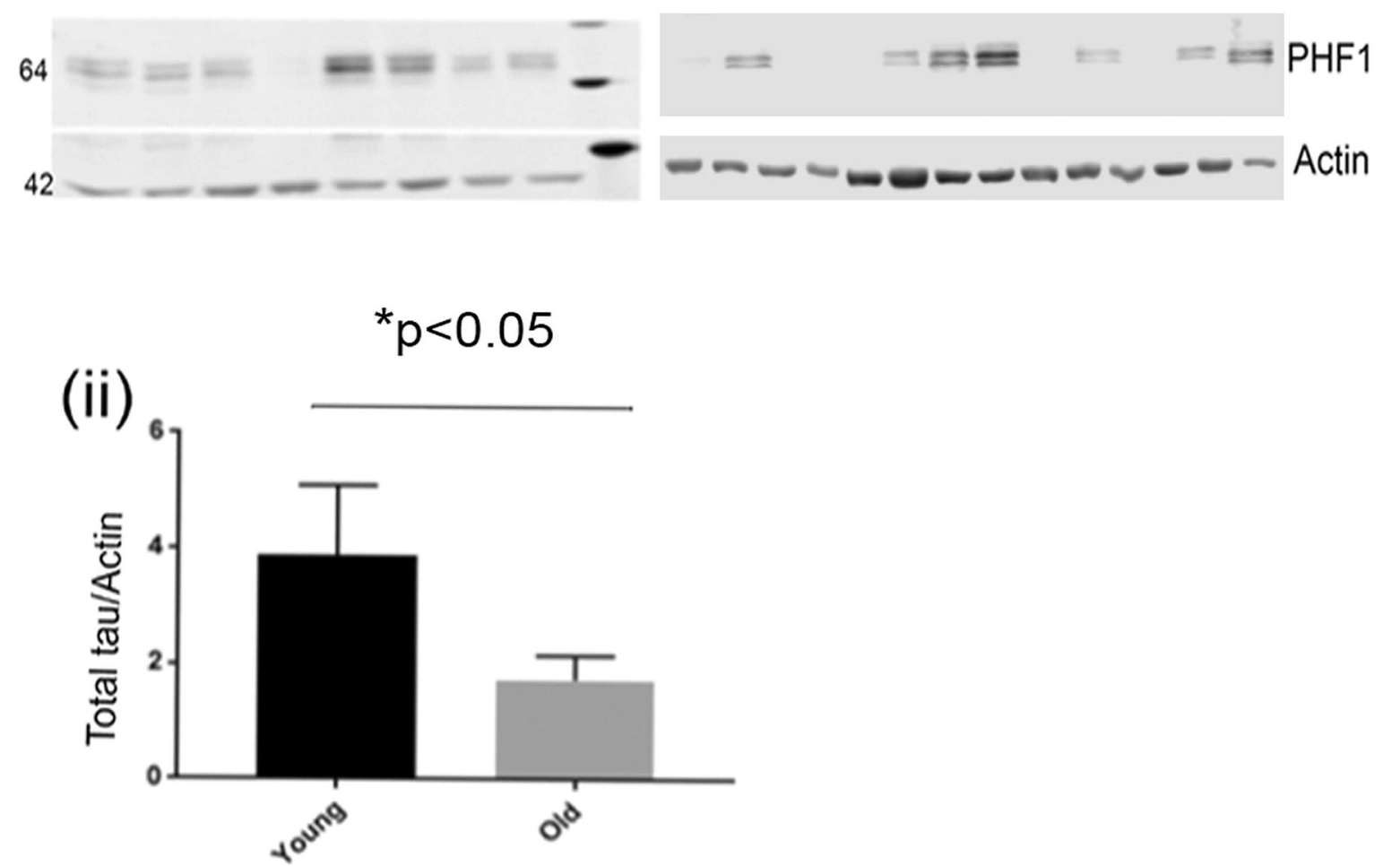

Age/years

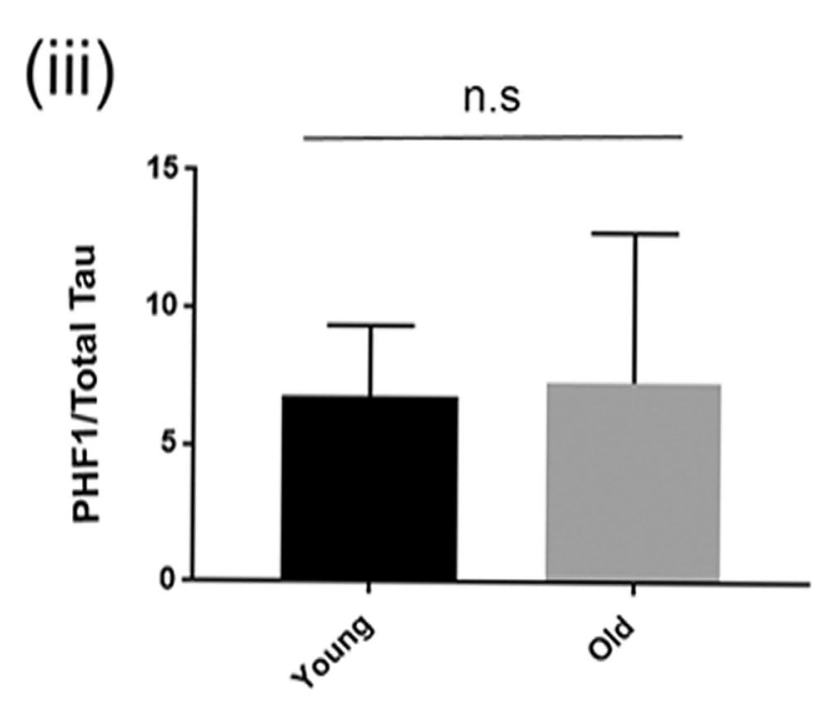

Age/years 


\section{A Postmortem Brain}

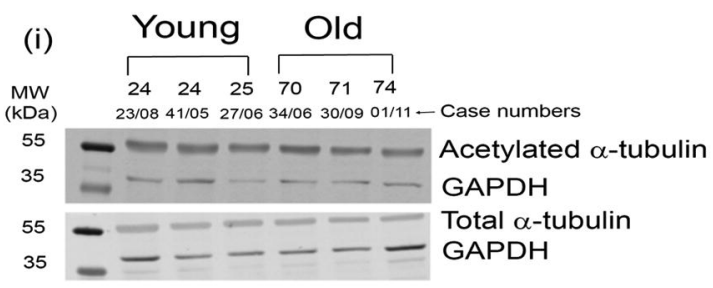

(ii)

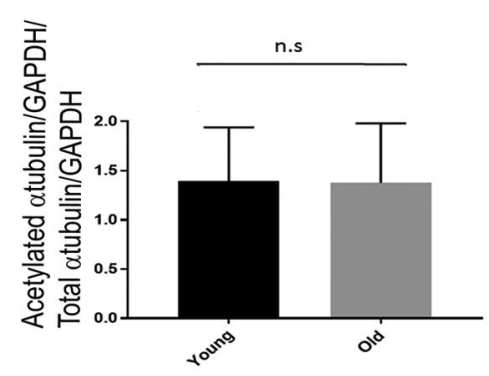

Age/years

\section{B Postmortem Brain}

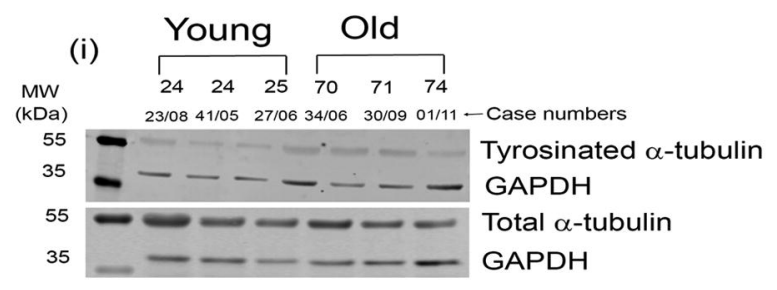

(ii)

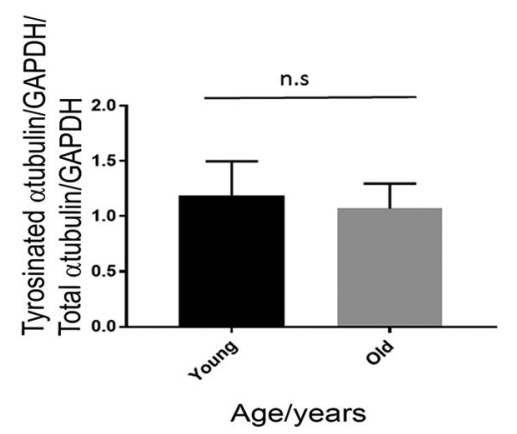




\section{A Postmortem Brain}

(i)

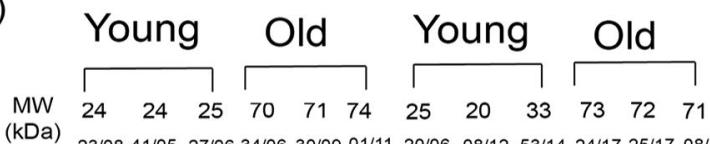

(kDa) 23/08 41/05 27/06 34/06 30/09 01/11 20/06 08/12 53/14 24/17 25/17 08/17 - Case numbers 60

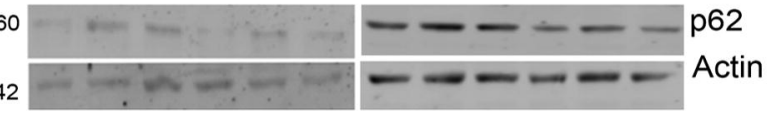

(ii)

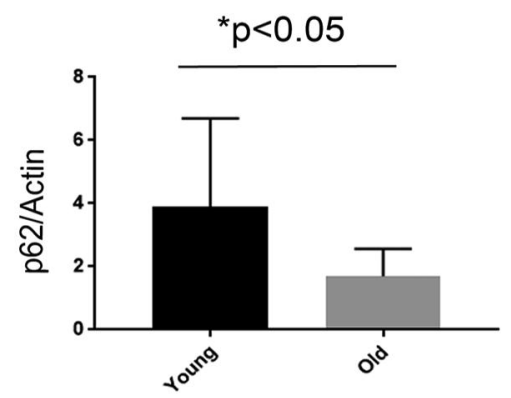

Age/years

\section{B Postmortem Brain}

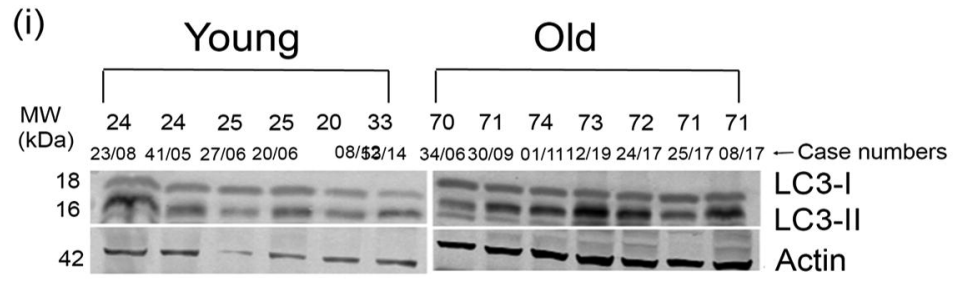

(ii)
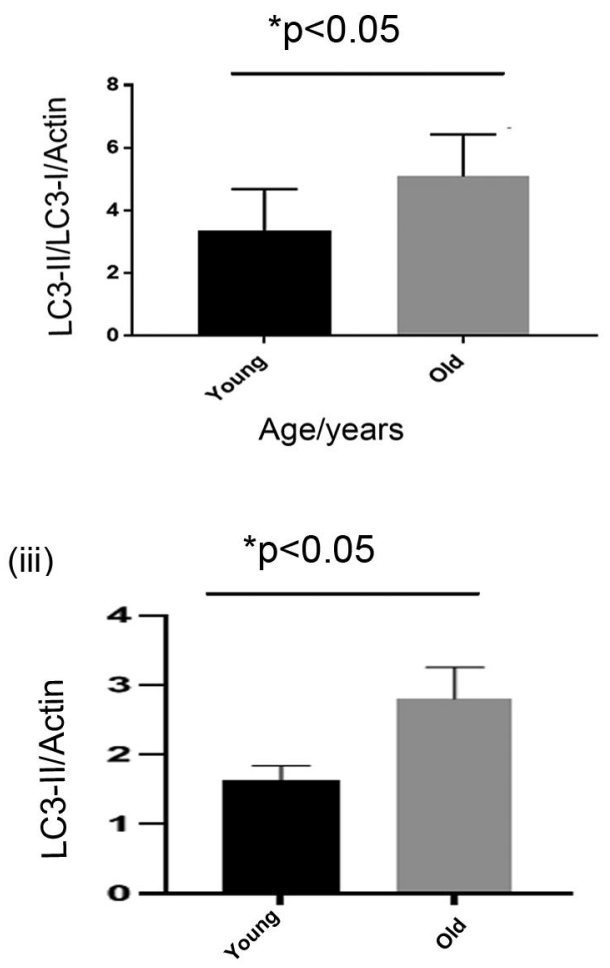

Age/years 


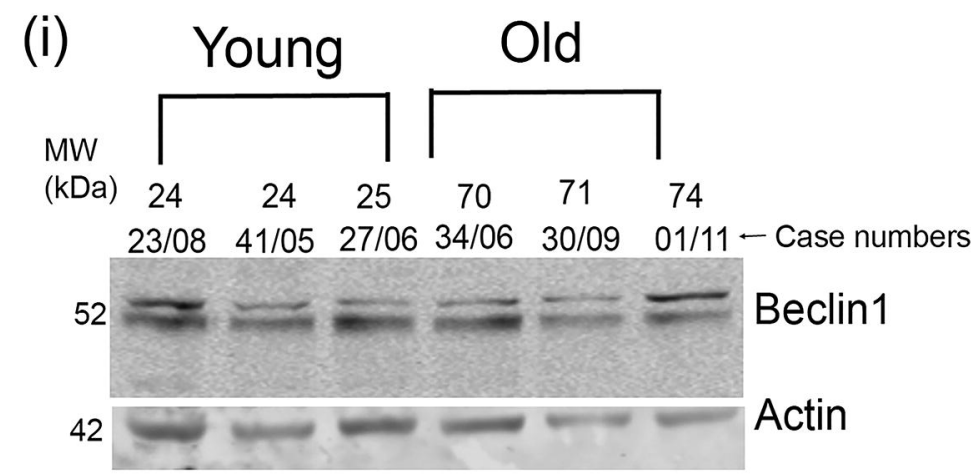

(ii)

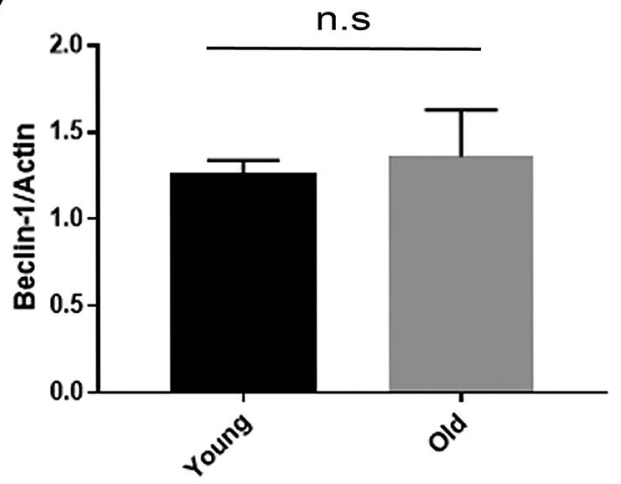

Age (years) 
A

(i)

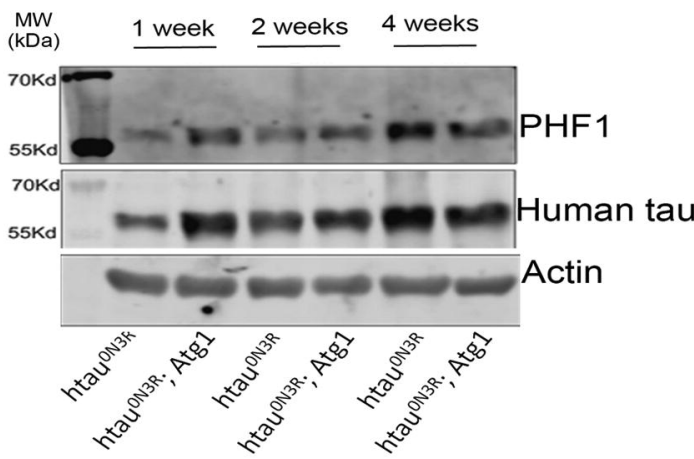

(ii)

\section{B}

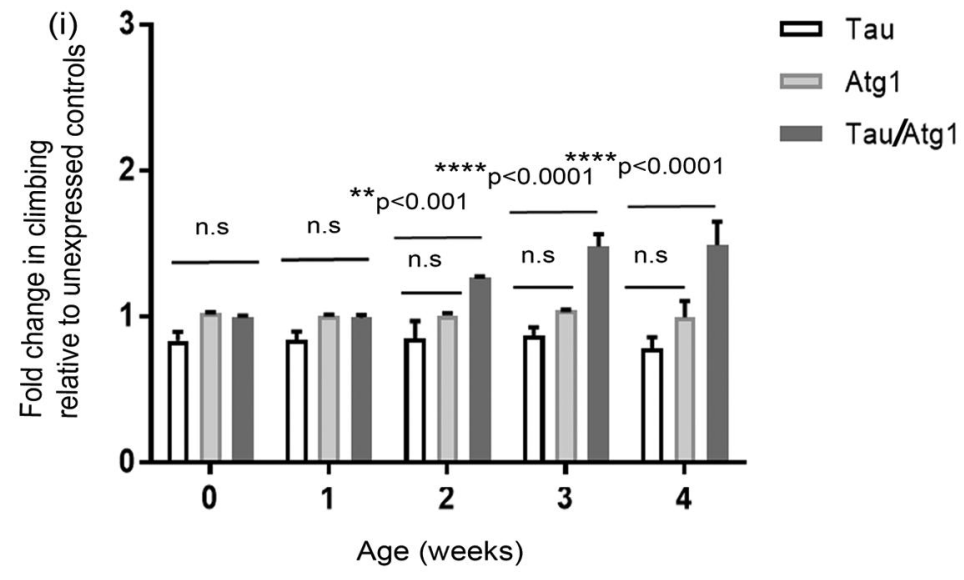

htauON3R

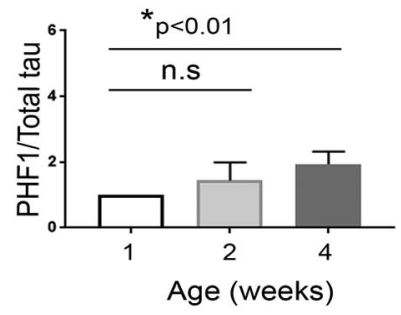

htau0N3R; Atg1

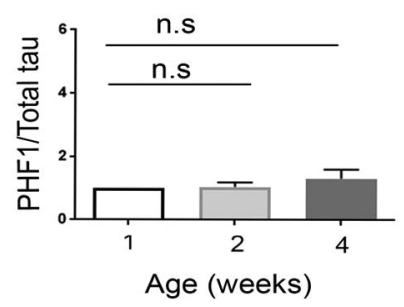

